\title{
Biosorption of Microelements by Spirulina: Towards Technology of Mineral Feed Supplements
}

\author{
Agnieszka Dmytryk, Agnieszka Saeid, and Katarzyna Chojnacka \\ Institute of Inorganic Technology and Mineral Fertilizers, Wrocław University of Technology, Smoluchowskiego 25, \\ 50-372 Wrocław, Poland \\ Correspondence should be addressed to Agnieszka Saeid; agnieszka.saeid@pwr.edu.pl
}

Received 4 April 2014; Revised 21 July 2014; Accepted 21 July 2014; Published 23 September 2014

Academic Editor: Maurício L. Torem

Copyright (C) 2014 Agnieszka Dmytryk et al. This is an open access article distributed under the Creative Commons Attribution License, which permits unrestricted use, distribution, and reproduction in any medium, provided the original work is properly cited.

\begin{abstract}
Surface characterization and metal ion adsorption properties of Spirulina sp. and Spirulina maxima were verified by various instrumental techniques. FTIR spectroscopy and potentiometric titration were used for qualitative and quantitative determination of metal ion-binding groups. Comparative FTIR spectra of natural and $\mathrm{Cu}(\mathrm{II})$-treated biomass proved involvement of both phosphoryl and sulfone groups in metal ions sorption. The potentiometric titration data analysis provided the best fit with the model assuming the presence of three types of surface functional groups and the carboxyl group as the major binding site. The mechanism of metal ions biosorption was investigated by comparing the results from multielemental analyses by ICP-OES and SEM-EDX. Biosorption of $\mathrm{Cu}(\mathrm{II}), \mathrm{Mn}(\mathrm{II}), \mathrm{Zn}(\mathrm{II})$, and $\mathrm{Co}(\mathrm{II})$ ions by lyophilized Spirulina sp. was performed to determine the metal affinity relationships for single- and multicomponent systems. Obtained results showed the replacement of naturally bound ions: $\mathrm{Na}(\mathrm{I}), \mathrm{K}(\mathrm{I})$, or $\mathrm{Ca}$ (II) with sorbed metal ions in a descending order of $\mathrm{Mn}(\mathrm{II})>\mathrm{Cu}(\mathrm{II})>\mathrm{Zn}$ (II) $>\mathrm{Co}$ (II) for single- and $\mathrm{Cu}(\mathrm{II})>\mathrm{Mn}$ (II) $>\mathrm{Co}(\mathrm{II})>\mathrm{Zn}$ (II) for multicomponent systems, respectively. Surface elemental composition of natural and metalloaded material was determined both by ICP-OES and SEM-EDX analysis, showing relatively high value of correlation coefficient between the concentration of $\mathrm{Na}(\mathrm{I})$ ions in algal biomass.
\end{abstract}

\section{Introduction}

Biosorption properties of Spirulina have been adapted in many techniques related with metal pollution control $[1-3]$. Industrial wastewater treatment or, generally, bioremediation of aquatic systems was the subject of several investigations [4-9], including smelter and refinery effluents processing [10]. Besides heavy metal ions, removal of inorganic contaminants $[11,12]$ and toxic organics was investigated [13], as well. Despite proven efficacy of Spirulina biomass, Chlorella species were reported as the most commonly used in current treatment technologies [14]. Nevertheless, other potential applications of Spirulina adsorptive capacity, such as livestock feeding and human dietary supplementation, have been already discussed in the literature [15-18]. Further studies on using this microalga as versatile biosorbent are therefore justified, since they may provide insights into both the process pathways and the mechanism of sorption.
Strong molecular interactions, in particular electrostatic attractions, determine the quality of biosorbents and depend on chemical state and composition (type and quantity) of surface functional groups. The state of surface moieties, their ionization or protonation, results directly from dissociation constant $\left(\mathrm{pK}_{a}\right.$ or $\mathrm{pK}_{b}$, in fact) and medium acidity $(\mathrm{pH})$. Usually, value of this constant for chemical moiety in biomolecules closely corresponds to $\mathrm{pK}$ value of appropriate inorganic acid or base. The presence of different types of functional groups, commonly: carboxyl, phosphoryl, sulfone, hydroxyl, and amine groups on biomass surfaces, causes that the biomass has amphoteric properties. Depending on $\mathrm{pH}$, acid or base character may be more or less apparent. Protonated amines are positively charged, while deprotonated are neutral. In the case of carboxyl, phosphoryl or sulfone groups, protonation neutralizes those groups, while removal of protons forms negatively charged conjugate bases [19-21]. It is especially important when concerning biomass interaction 


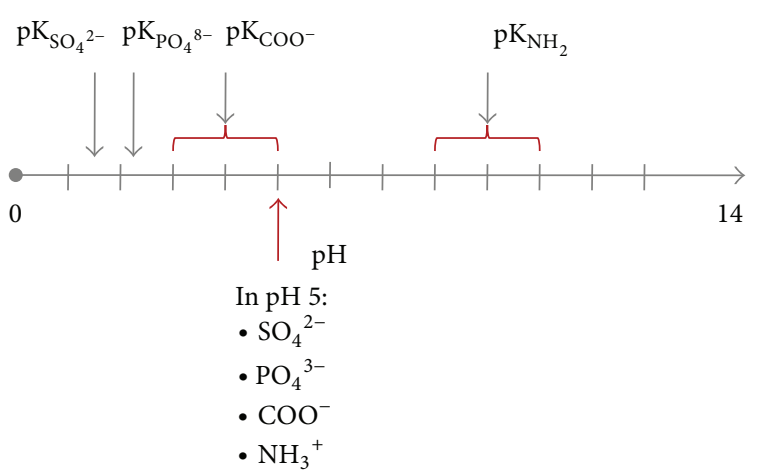

FIGURE 1: The state of ionization of functional groups on the surface of the microalgal cell wall depending on $\mathrm{pH}$.

with different ions and the fact that electrical charge of biomass surface, governs sorbates adsorption. For example, the isoelectric point ( $\mathrm{pI}$ ) of microalgae Chlorella is about 3 , while Spirulina $\mathrm{pI}=2.8-3.5$ [19]. In lower $\mathrm{pH}$, positively charged groups (e.g., amine group) attract anions and repulse cations, while in higher $\mathrm{pH}$ negatively charged groups (e.g., carboxyl) act conversely. Typical changes of ionization state of functional groups on the surface of microalgae cell wall depending on $\mathrm{pH}$ are shown in Figure 1, along with the listing of functional groups (under the red arrow) and their forms in $\mathrm{pH}=5$, for which the highest model parameters from quantitative and kinetic examination have been obtained [20].

In present work, dried biomass of commercially available Spirulina sp. (lyophilisate) and cultivated under laboratory conditions Spirulina maxima were investigated for supplementation with microelement ions: $\mathrm{Cu}(\mathrm{II}), \mathrm{Co}(\mathrm{II})$, $\mathrm{Mn}(\mathrm{II})$, and $\mathrm{Zn}(\mathrm{II})$, which are important in livestock feeding. Biosorption experiments were performed in both singleand multicomponent systems, under previously evaluated conditions. Four analytical methods were used to assess the composition of natural and loaded biomass surface, as well as to verify the biosorption mechanism, in exchange, posited on the basis of earlier studies. The major binding sites were identified along with their concentrations, and thus total capacity of both examined biosorbents might be estimated. Based on changes observed in elemental composition of the Spirulina surface after biosorption experiments, the affinity sequence of microelement cations was determined for single- and multimetal systems separately. The applicability of microalgal biomaterials to feed supplementation was assessed due to resultant of all conducted tests.

\section{Materials and Methods}

2.1. Microorganisms and Media Composition. Two kinds of algal biomasses were selected for biosorption research. Commercially available Spirulina sp. in form of lyophilized cells was purchased from SIGMA (USA). Spirulina maxima was obtained from Culture Collection of Algal Laboratory (CCALA) Institute of Botany, Academy of Sciences of the

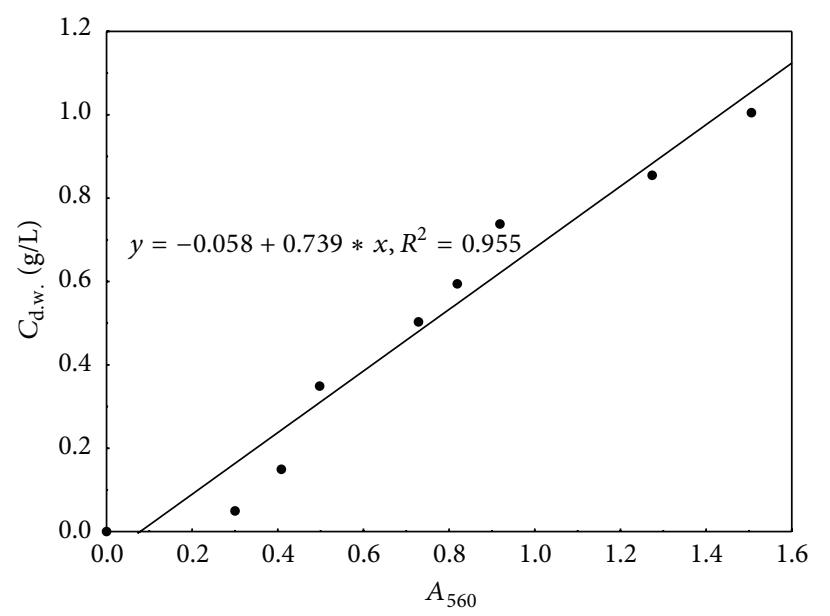

FIGURE 2: Standard curve represents the relationship between concentration of Spirulina maxima dry mass $\left(C_{\text {d.w. }}\right)$ and corresponding absorbance $\left(A_{560}\right)$ results.

Czech Republic. Microalga grew in the Schlösser liquid medium [22], composition of which is presented in Table 1.

Schlösser culture medium was prepared with analytical grade reagents and purchased from POCh S.A. (Gliwice, Poland). After cultivation, the biomass was separated by filtration, using the aquarium algae vacuum cleaner (Actizoo Zolux, France), dried at $60^{\circ} \mathrm{C}$ (laboratory oven, WAMED; Warsaw, Poland) for three days, and subjected to further investigation as a biosorbent.

2.2. Cultivation of Spirulina maxima. Spirulina maxima was cultivated in laboratory-scale reactors, at $35^{\circ} \mathrm{C}$ [23] for 4 months. The cultures were carried out under 12:12 photoperiod conditions ( $12 \mathrm{hr}$ light : $12 \mathrm{hr}$ dark cycles), provided with artificial illumination of $19 \mathrm{~W} \mathrm{~m}^{-2}$ intensity. In order to improve growth, algal scalability tests were performed in three consecutive systems of increasing capacity. Microalga cultivation started with a working capacity of $1 \mathrm{~L}$ and, due to cell passaging, $5 \mathrm{~L}$ and $40 \mathrm{~L}$ reactor systems were examined, as well.

The efficiency of the Spirulina maxima cultivation in each of tested capacities was determined using three basic parameters: the concentration of microalgal culture, growth rate, and relative (exponential) growth rate. The first of three $\left(C_{S}\right)$ was estimated by the straight-line equation showing the correlation between concentration of microalga dry mass and absorbance measurements at $560 \mathrm{~nm}$ (Figure 2).

2.3. Semibatch Mode. The experiment was conducted on Spirulina maxima culture and grown in Schlösser medium at $35^{\circ} \mathrm{C}$, using $40 \mathrm{~L}$-working capacity reactor equipped with two light sources (12:12 photoperiod) (Figure 3). The cultivation was carried out for 4 months.

During research, the systematic partial reception of microalgal biomass was performed to diminish the selfshading effect, which was verified by cell concentration measurements. The biomass was separated by vacuum filtration (Actizoo Zolux, France) seven times overall. The last separation stage gathered whole population of grown 


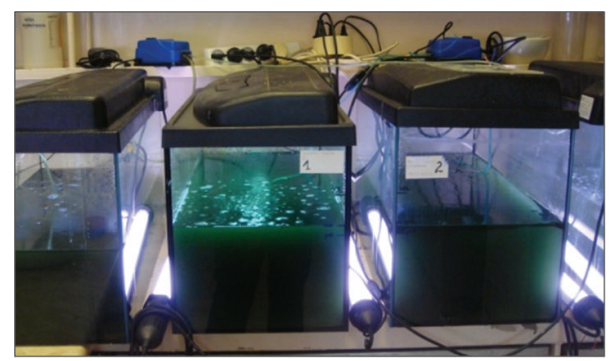

FIgURE 3: Spirulina maxima cultivation carried out in laboratory scale system of $40 \mathrm{~L}$.

Spirulina maxima, in which cells after 3-day drying at $60^{\circ} \mathrm{C}$ (WAMED; Warsaw, Poland) were examined on biosorption properties in adequate tests described below.

2.4. Metal Ions Biosorption Experiments. Biosorption experiments were performed for copper(II), cobalt(II), manganese(II), and zinc(II) ions in both single- and multimetal systems, according to the procedure used in previous work [15]. Tests were carried out in a batch mode, at equal initial ion concentrations $300 \mathrm{mg} \mathrm{L}^{-1}$ at $35^{\circ} \mathrm{C}$ (Spirulina cultivation temperature) and $\mathrm{pH}$ 5. The microalgal biosorbent was examined at a concentration of $1 \mathrm{~g} \mathrm{~L}^{-1}$. The solutions of metal ions were prepared in deionized water with appropriate amounts of inorganic salt (from POCh S.A. Gliwice, Poland): $\mathrm{Co}\left(\mathrm{NO}_{3}\right)_{2} \cdot 5 \mathrm{H}_{2} \mathrm{O}, \mathrm{CuSO}_{4} \cdot 5 \mathrm{H}_{2} \mathrm{O}$, $\mathrm{MnSO}_{4} \cdot 5 \mathrm{H}_{2} \mathrm{O}, \mathrm{ZnSO}_{4} \cdot 7 \mathrm{H}_{2} \mathrm{O}$. $\mathrm{pH}$ of the metal ion solution was measured using Mettler Toledo Seven Multi-pH-meter (Greifensee, Switzerland) equipped with a temperaturecompensating electrode InLab413. $\mathrm{pH}$ adjustment to the endpoint was performed with standardized $\mathrm{NaOH}$ or $\mathrm{HCl}$ solution ( $0.1 \mathrm{~mol} \mathrm{~L}^{-1}$; POCh S.A. Gliwice, Poland). The biosorption experiments were conducted in Erlenmeyer flasks containing $100 \mathrm{~mL}$ of $\mathrm{Cu}$ (II), $\mathrm{Co}$ (II), $\mathrm{Mn}$ (II), and $\mathrm{Zn}$ (II) synthetic solutions, shaken in thermostated water bath shaker at $150 \mathrm{rpm}$ speed. The contact time of 60 minutes was evaluated for Spirulina biomass based on previous kinetic research [15]. After completion of each test, the microalgal suspension was separated by filtration through the filter papers, oven dried (WAMED; Warsaw, Poland), and further analyzed.

2.5. Fourier Transform Infrared (FTIR) Spectroscopy. FTIR spectroscopy was used to identify microalgal cell wall functional groups participating in biosorption by detection of vibration wave number changes in the sorbent surface, occurred after metal ion binding. FTIR measurements were thus performed for natural S. maxima dried cells and the same biomass enriched in $\mathrm{Cu}(\mathrm{II})$ (model single-metal system). In order to verify diversity of surface functional groups for different microalgal biosorbent, pristine Spirulina sp. lyophilisate was examined, as well. Before analyzing, a few milligrams of each alga, including $\mathrm{Cu}$ (II)-loaded S. maxima, were ground and mixed with potassium bromide disks in an amount provided the biomaterial concentration of $2 \%$, by
TABLE 1: The composition of the Schlösser medium.

\begin{tabular}{|c|c|}
\hline Component & Concentration, $\mathrm{g} \mathrm{L}^{-1}$ \\
\hline $\mathrm{NaHCO}_{3}$ & 13.61 \\
\hline $\mathrm{Na}_{2} \mathrm{CO}_{3}$ & 4.03 \\
\hline $\mathrm{K}_{2} \mathrm{HPO}_{4}$ & 0.5 \\
\hline $\mathrm{NaNO}_{3}$ & 2.5 \\
\hline $\mathrm{K}_{2} \mathrm{SO}_{4}$ & 1.0 \\
\hline $\mathrm{NaCl}$ & 1.0 \\
\hline $\mathrm{MgSO}_{4} \cdot 7 \mathrm{H}_{2} \mathrm{O}$ & 0.2 \\
\hline $\mathrm{CaCl}_{2}$ & 0.03026 \\
\hline $\mathrm{FeSO}_{4} \cdot 7 \mathrm{H}_{2} \mathrm{O}$ & 0.01 \\
\hline EDTA & 0.08 \\
\hline \multicolumn{2}{|c|}{ Microelement solution, $\mathrm{g} \mathrm{L}^{-1}$} \\
\hline $\mathrm{ZnSO}_{4} \cdot 7 \mathrm{H}_{2} \mathrm{O}$ & 1.0 \\
\hline $\mathrm{MnSO}_{4} \cdot 5 \mathrm{H}_{2} \mathrm{O}$ & 2.0 \\
\hline $\mathrm{H}_{3} \mathrm{BO}_{3}$ & 5.0 \\
\hline $\mathrm{Co}\left(\mathrm{NO}_{3}\right)_{2} \cdot 6 \mathrm{H}_{2} \mathrm{O}$ & 5.0 \\
\hline $\mathrm{Na}_{2} \mathrm{MoO}_{4} \cdot 2 \mathrm{H}_{2} \mathrm{O}$ & 5.0 \\
\hline $\mathrm{CuSO}_{4} \cdot 5 \mathrm{H}_{2} \mathrm{O}$ & 1.0 \\
\hline $\mathrm{FeSO}_{4} \cdot 7 \mathrm{H}_{2} \mathrm{O}$ & 0.7 \\
\hline EDTA & 0.8 \\
\hline Deionized water & 981 \\
\hline
\end{tabular}

mass. The FTIR spectra of prepared samples were collected by the use of a Perkin-Elmer System 2000 (Waltham, MA, USA) equipped with deuterated triglycine sulfate (DTGS) and mercury cadmium telluride (MCT) detector. The assay was conducted within the wave number range of $400-4000 \mathrm{~cm}^{-1}$ (midinfrared region) using a potassium bromide window, at room temperature $\left(26 \pm 1^{\circ} \mathrm{C}\right)$ [24]. FTIR spectra were elaborated with a System 2000-compatible software (PerkinElmer; Waltham, MA, USA), by use of which background calculation was performed to set necessary entries for result assessment. Obtained background, corresponding to pure $\mathrm{KBr}$, was automatically subtracted from each sample spectrum. All spectra were plotted using the same scale on the transmittance axis.

2.6. Potentiometric Titration of the Biomass. Potentiometric titration was performed to more specifically identify ion-binding groups, compared to FTIR spectroscopy, and to determine their concentrations onto microalgal cell wall. Measurements were conducted with both microalgal biomasses, according to the method elaborated in previous works $[20,24]$. Biomass samples of $0.2 \mathrm{~g}$ suspended in deionized water $(200 \mathrm{~mL})$ were titrated with $0.1 \mathrm{M} \mathrm{NaOH}$ till $\mathrm{pH}$ 11.5 and reversely with $0.1 \mathrm{M} \mathrm{HCl}$ till $\mathrm{pH} 2.5$, both solutions were standardized (POCh S.A., Gliwice, Poland). The $\mathrm{pH}$ change was monitored after single dose of titrant, when the record stabilization was achieved. As control (blank) sample, deionized water was used. Before each titration test, the water was purged of dissolved $\mathrm{CO}_{2}$ by 3-hour bubbling with argon. Ray (SEM-EDX) Analytical System. SEM-EDX analysis was 
carried out at Wrocław University of Environmental and Life Sciences (Electron Microscope Laboratory) to investigate the biosorption effect on element content of biomass cell wall, including both micro- and macroelements, and map the distribution of ions bound to its surface, as it was reported by Michalak and coworkers [25]. Tests were conducted using pristine and ion-enriched cells of lyophilized Spirulina sp., loaded with $\mathrm{Co}(\mathrm{II}), \mathrm{Cu}(\mathrm{II}), \mathrm{Mn}(\mathrm{II})$, and $\mathrm{Zn}(\mathrm{II})$ cations in both single- and multimetal system. Microalgal samples, a total of six, were fixed in $2.5 \%$ of glutaraldehyde (Sigma, http://www.sigmaaldrich.com/) and next dehydrated by ethanol (from 30\% till 100\% concentration). Treated biomass were sampled and prepared in two planes, enabling to observe cross-section and its surface. All samples were mounted on proper stub and gold sputtered thereafter using HHV Scancoat Six equipment (Crawley, Oxfordshire, UK). Observation and photographs of microalgae surface composition were taken with a Leo Zeiss 435 VP SEM scanning electron microscope (Oberkochen, Germany), operating at $20 \mathrm{kV}$. An additional equipment of the microscope was a RÖNTEC GmbH energy dispersive X-ray system (Berlin, Germany), by which the concentration of particular cell wall constituent was recorded. As a result, the X-ray spectra of elemental composition, specific for natural and metal ionenriched Spirulina sp. surface were obtained.

2.8. Inductively Coupled Plasma-Optical Emission Spectrometry (ICP-OES). ICP-OES technique was used to determine and compare total content of the elements in microalgal biosorbent before and after metal ion binding. This analysis was proven to be precise and appropriate in evaluation of biosorption efficacy, considering applicability to feed supplementation in particular [26]. In conducted research, ICP-OES was performed as a complementary analysis to SEM-EDX system, intended for verification of the scanning electron microscopy usefulness to record and elaborate data from biosorption experiments with Spirulina. Measurements were carried out on Spirulina sp. samples with and without metal ion enrichment, using VISTA-MPX spectrometer (Varian; Victoria, Australia) with ultrasonic nebulizer in the Chemical Laboratory of Multielemental Analyses at Wrocław University of Technology accredited by ILAC-MRA (Varian VISTA-MPX ICP-OES) and the Polish Centre for Accreditation (number AB 696). According to formerly elaborated procedure [15], microalgal samples of c.a. $0.5 \mathrm{~g}$ suspended in $5 \mathrm{~mL}$ of $65 \%$ nitric acid Suprapur from EMD Millipore (Merck KGaA; Darmstadt, Germany) were subjected to pressure microwave digestion (mineralization) in Teflon vessels using microwave oven Milestone MLS-1200 (Sorisole, Bergamo, Italy). After mineralization, all samples were diluted to $50 \mathrm{~mL}$ and the concentrations of metal ions were detected spectrometrically (VISTA-MPX, Australia) in triplicate. The apparatus was calibrated with standard solutions $\left(1.0,10,50\right.$, and $\left.100 \mathrm{mg} \mathrm{L}^{-1}\right)$, prepared based on the $100 \mathrm{mgL}^{-1}$ multielemental standard Astasol (Prague, Czech Republic). Optimization of the test parameters was performed as described before [26]. The analytical process of digested biomass samples was controlled by the use of Polish

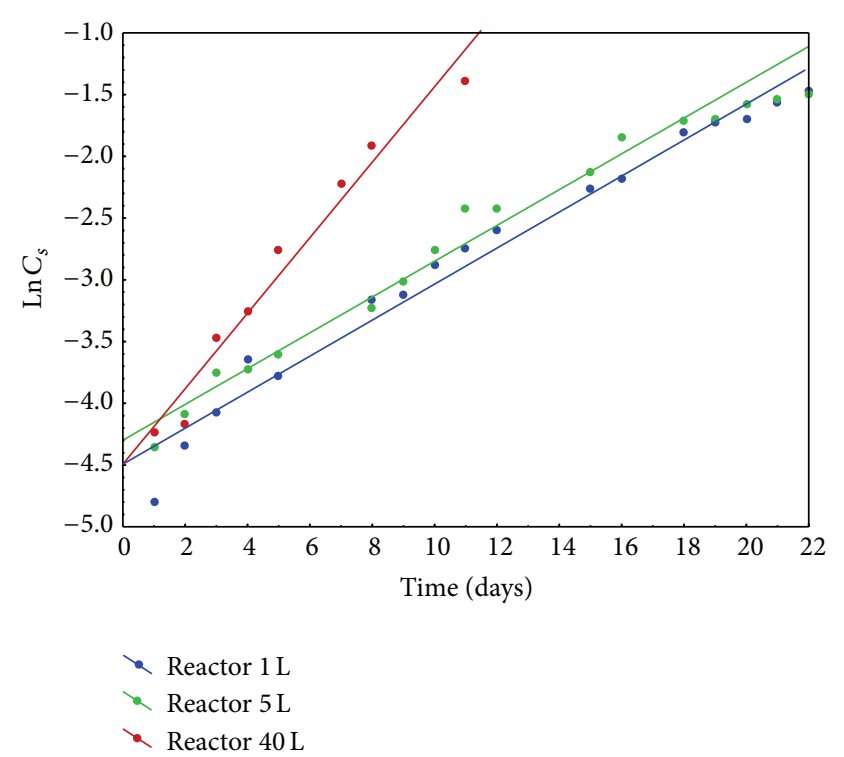

FIGURE 4: Correlation between Spirulina maxima concentration, expressed as natural logarithm and cultivation time for three tested systems.

Certified Reference Material for multielement trace analysis, Oriental Tobacco Leaves (CTAOTL-1), obtained from the Institute of Nuclear Chemistry and Technology (Poland, http://www.ichtj.waw.pl/drupal/) [26].

\section{Results and Discussion}

3.1. Reactor Capacity Selection for Spirulina maxima Cultivation. Three comparative experiments in $1 \mathrm{~L}-, 5 \mathrm{~L}-$, and $40 \mathrm{~L}$-capacity reactor were performed to select the working scale, in which Spirulina maxima would be cultivated most effectively. The biomass yield was verified by comparison of growth rate and relative growth rate results, obtained for each cultivation.

Relative growth rate $(\mu)$ is an experimental value, specific to particular microbial system. $\mu$ is proportional to biomass concentration increase during the logarithmic growth phase over a certain time period, which is expressed by

$$
\begin{gathered}
\mu=\frac{\ln C_{S}^{t}-\ln C_{S}^{0}}{t}, \\
{[\mu]=\left[\text { day }^{-1}\right],}
\end{gathered}
$$

where $t$ : time period, after which the culture concentration was measured (assuming $t^{0}=0$ ), $C_{S}^{t}$ : the culture concentration after time $t$, and $C_{S}^{0}$ : the initial concentration of the culture. Relative growth rate is usually determined from the graphically depicted correlation of $\ln C_{S}=f(t)$ (Figure 4). The linear regression is described by

$$
\ln C_{S}^{t}=\mu \cdot t+\ln C_{S}^{0}
$$

and parameter $\mu$ is the slope. 
TABLE 2: Relative growth rate of continuous cultures in the reactors of different volumes.

\begin{tabular}{lcc}
\hline Capacity, $\mathrm{L}$ & $\mu$ day $^{-1}$ & $R^{2}$ \\
\hline 1 & 0.145 & 0.973 \\
5 & 0.145 & 0.978 \\
40 & 0.285 & 0.987 \\
\hline
\end{tabular}

TABLE 3: Relative growth rates of Spirulina maxima cells in culture with biomass reception.

\begin{tabular}{lcc}
\hline Time interval & $\mu$, day $^{-1}$ & $R^{2}$ \\
\hline I & 0.285 & 0.987 \\
II & 0.0439 & 0.990 \\
III & 0.0503 & 0.985 \\
IV & 0.0464 & 0.976 \\
V & 0.0331 & 0.949 \\
VI & 0.0275 & 0.876 \\
VII & 0.0281 & 0.923 \\
\hline
\end{tabular}

Results of relative growth rate obtained for Spirulina maxima cultures that grew in reactors with all selected capacities were presented in Table 2.

Full characterization of the microbial cultivation required evaluation of biomass growth rate $\left(r_{x}\right)$, as well. This parameter is expressed by proportional relationship between relative growth rate and the culture concentration in exact time of measurement as follows:

$$
\begin{gathered}
r_{x}=\mu \cdot C_{S}^{t}, \\
{\left[r_{x}\right]=\left[\mathrm{g} \cdot \mathrm{L}^{-1} \cdot \text { day }^{-1}\right] .}
\end{gathered}
$$

Changes in values of growth rate during two first weeks of the research, including each examined system, are depicted in Figure 5.

Considering obtained results of growth rate and relative growth rate, the explicit correlation between reactor capacity and cultivation yield was noted. The lower the capacity system was used, the lower the rate of microalga growth was achieved. Such disparities were likely caused by self-shading effect. The highest of tested capacities was confirmed to be, simultaneously, the most effective. Thus, it was decided to cultivate Spirulina maxima cultures, destined for biosorption experiments, in $40 \mathrm{~L}$ reactor working volume in semibatch mode (Section 3.2).

3.2. Semibatch Mode in 40 L Reactor System. Semibatch mode was used to optimize Spirulina maxima growth during 4month cultivation. Except the biomass separation at the end of test, microalga cells were filtered out in the meantime, when stabilization of their concentration was noted (lag phase beginning). The next day after each of six partial receptions performed, a renewed increase in the biomass concentration was recorded (Figure 6).

Due to performing cultivation in semibatch mode, seven distinctive relative growth rates were evaluated, summary of which is presented in Table 3.

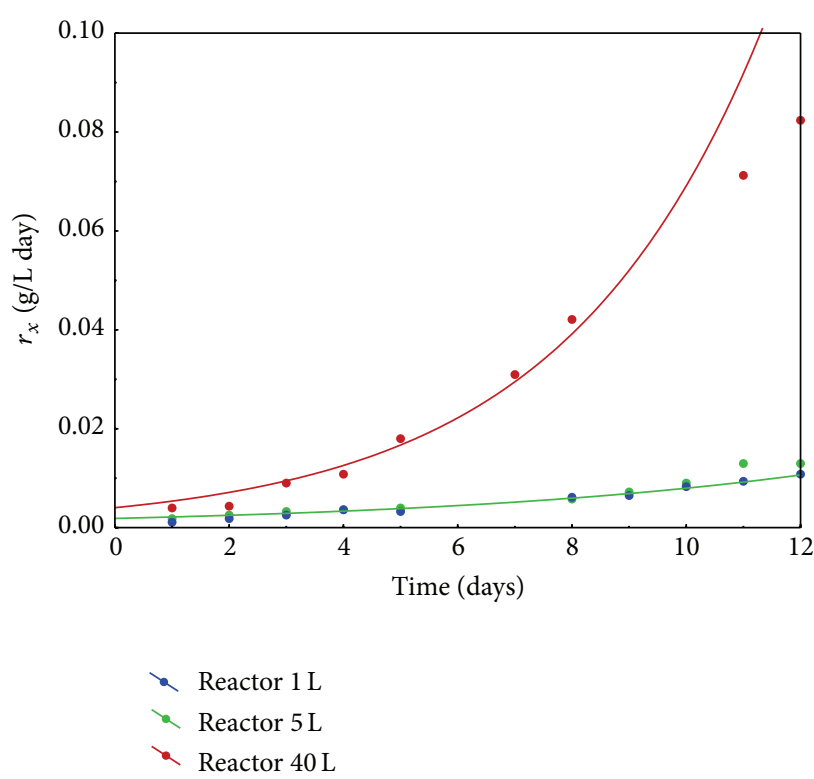

FIGURE 5: Comparison of Spirulina maxima growth rates for cultures in different capacities during two first weeks of cultivation.

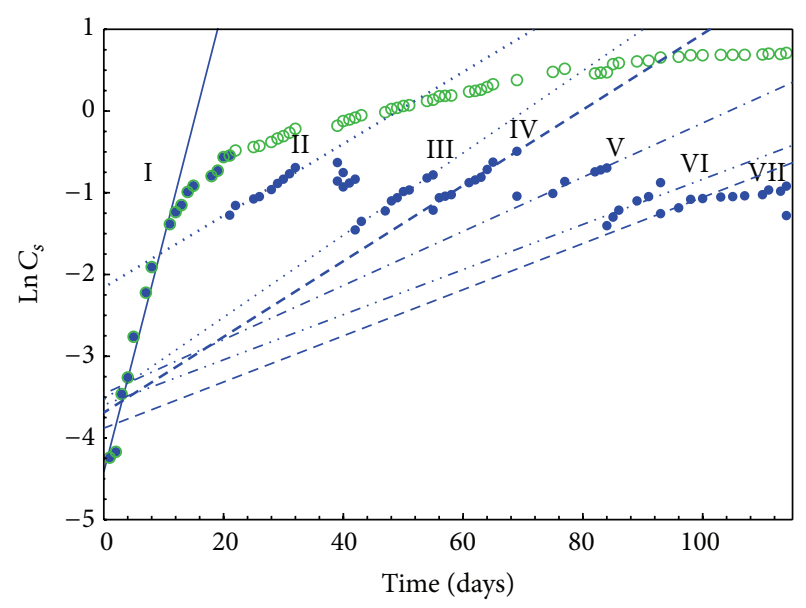

FIGURE 6: Kinetics of Spirulina maxima growth in semibatch culture.

The subsequent biomass separations resulted in $\mu$ decrease. It was noticed that average of the relative rate values II-VII (0.0382 day $\left.^{-1}\right)$ was $87 \%$ lower compared with the rate achieved at the beginning of the culture $\left(0.285\right.$ day $\left.^{-1}\right)$. Limiting the relative growth rate was likely related to medium alkalization, caused by the microbial consumption of $\mathrm{CO}_{2}$, released as a product of medium constituent decomposition $\left(\mathrm{HCO}_{3}{ }^{-} \rightleftarrows \mathrm{CO}_{2}+\mathrm{OH}^{-}\right)$.

Due to similarity of the rate results obtained after fifth and sixth exceeded biomass filtration ( $\mu$ numbers VI and VII), further cultivation was discontinued and followed with biosorption research using, previously dried, microalga cells.

3.3. Fourier Transform Infrared Spectroscopy. FTIR analysis was confirmed as efficacy method for identification of both 


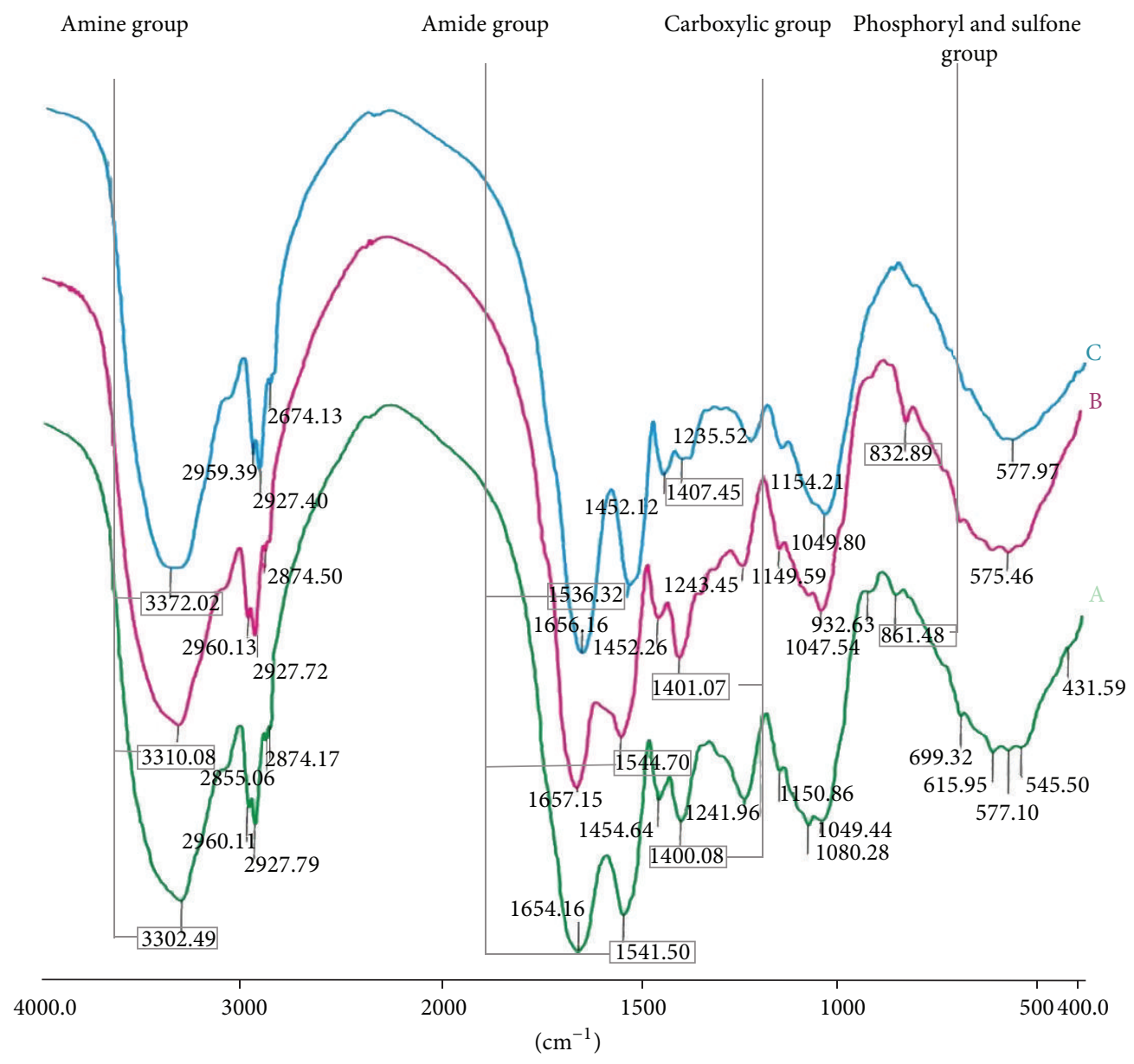

FIGURE 7: Normalized FTIR absorption spectrum of selected functional groups exposed on cell wall surface of microalgae biomass. A (green line) pristine Spirulina sp., B (pink line) pristine Spirulina maxima and C (blue line) Cu(II)-enriched Spirulina maxima.

total and metal ion-binding groups occurred on the biosorbent surface [27]. Evaluation of the adsorptive properties of biological materials, including algae, with FTIR spectra was investigated in a number of reports. Many studies focused on applicability of seaweeds to aqueous media treatment by removing heavy metal ions, such as $\mathrm{Pb}(\mathrm{II}), \mathrm{Cd}(\mathrm{II}), \mathrm{Ni}(\mathrm{II})$, $\mathrm{U}(\mathrm{VI})$, and Th(IV) [28-30]. There are also some works, in which algal biomass is subjected to interactions with cations of nutritional value [24, 31]. However, no literature data was found to provide information on usability of Fourier transform infrared spectroscopy in evaluation of enrichment Spirulina species with microelements.

Results of FTIR analysis (Figure 7) proved the variety of functional groups found on the cell wall surface of examined biosorbents. Each group in its free form, that is, without metal ion loaded, was detected at strictly defined wave number, giving a specific signal (band). A set of all bands spectrum, which depicts the full surface composition of particular biomass is named as IR "fingerprint" [32].

Figure 7 shows the bands representing the specific groups detected on the cell wall of pristine and $\mathrm{Cu}(\mathrm{II})$-loaded Spirulina maxima (Figures $7(\mathrm{~B})$ and $7(\mathrm{C})$, resp.), as well as lyophilized Spirulina sp. (Figure $7(\mathrm{~A})$ ). Spectra of both natural microalgal biomasses proved their great similarity in the composition of surface groups. At the same time, small differences in the wave number, at which particular band was noted, confirmed the efficacy of FTIR analysis in identifying samples of biological material. Run sequence plot of ionenriched microalga differed, at some points, from pristine microalgae results due to interactions of cell wall groups with metal cations, which caused visible signal changes.

Considering spectra of natural biosorbent surface, a few functional groups might be identified. At the highest wave number of $3,300-3,310 \mathrm{~cm}^{-1}$ amine bands were detected. Stretching bands at $1,650 \mathrm{~cm}^{-1}$ (asymmetrical) and $1,400 \mathrm{~cm}^{-1}$ (symmetrical) corresponded to carbonyl groups $(\mathrm{C}=\mathrm{O})$ of protein primary amides and carboxylate ions, respectively. The band at $1,540 \mathrm{~cm}^{-1}$ represented the stretching vibrations of protein secondary amides $(-\mathrm{NH})$. The band at $1,240 \mathrm{~cm}^{-1}$ was given by free - $\mathrm{CO}$ bound, while stretching vibrations at 1,150 and $1,050 \mathrm{~cm}^{-1}$ corresponded to $\mathrm{CC} / \mathrm{CO}$ mode of polysaccharides ethers. Within a wave number range of 1,240-1,050 $\mathrm{cm}^{-1}$ hydroxyl bands were detected, as well. The detailed summary of all bands observed on the microalgae spectra was shown in Table $4[33,34]$. 
TABLE 4: Identified functional groups on surface of natural and $\mathrm{Cu}(\mathrm{II})$-loaded Spirulina biomass.

\begin{tabular}{|c|c|c|c|c|}
\hline Bond & Spirulina sp. & $\begin{array}{l}\text { Spirulina maxima } \\
\text { Wave number, } \mathrm{cm}^{-1}\end{array}$ & $\begin{array}{l}\mathrm{Cu}(\mathrm{II})-\text { Spirulina } \\
\text { maxima }\end{array}$ & Component \\
\hline$\equiv \mathrm{P}-\mathrm{O}-,-\mathrm{SO}_{3}-$ & 861.48 & 832.89 & - & Polysaccharides \\
\hline$\gamma \mathrm{CC} / \mathrm{CO}, \gamma \mathrm{OH}$ & $\begin{array}{l}1049.44 \\
1150.86\end{array}$ & $\begin{array}{l}1047.54 \\
1149.59\end{array}$ & $\begin{array}{r}1049.80 \\
1154.21\end{array}$ & Polysaccharides, Polysaccharides ethers \\
\hline$\delta \mathrm{C}-\mathrm{O}-\mathrm{C}, \delta \mathrm{OH}$ & 1241.96 & 1243.45 & 1235.52 & Amides, Polysaccharides, Esters \\
\hline$\gamma_{\mathrm{S}} \mathrm{COO}^{-}$ & 1400.08 & 1401.07 & 1407.45 & Carboxyl group \\
\hline$\delta \mathrm{CH} / \mathrm{CH}_{2}$ & 1454.64 & 1452.26 & 1452.12 & Alkyl chain \\
\hline$\delta \mathrm{NH}$ & 1541.50 & 1544.70 & 1536.32 & Secondary amides \\
\hline$\gamma \mathrm{C}=\mathrm{O}, \gamma \mathrm{CN}$ & 1654.16 & 1657.15 & 1656.16 & Protein primary amides \\
\hline$\gamma_{\mathrm{S}} \mathrm{CH}_{3}$ & 2874.17 & 2874.50 & 2874.13 & Alkyl chain \\
\hline$\gamma_{\mathrm{AS}} \mathrm{CH}_{3}$ & 2927.79 & 2927.72 & 2927.40 & Alkyl chain \\
\hline$\gamma_{\mathrm{S}} \mathrm{CH}_{2}$ & 2960.11 & 2960.13 & 2959.39 & Alkyl chain \\
\hline$\gamma \mathrm{NH}_{3}$ & 3302.49 & 3310.08 & 3372.02 & Amines \\
\hline
\end{tabular}

The group(s) primarily concerned with metal ion interaction might be indicated with differences in vibration intensity (transmittance) or band wave number, noted between treated and nontreated biomass spectra. FTIR records for $\mathrm{Cu}(\mathrm{II})$ loaded biomaterial showed the characteristic peak shifting of amine group, which occurred at 60 units higher wave number, compared to nontreated microalgal cells. A small change in peak positions of secondary amide (lower wave number) and carboxyl (higher wave number) groups was also observed; however, obtained differences were not as evident as in the case of amine group. Thus, verification of significance of both amide and carboxyl groups in ion sorption was required. Nevertheless, the band intensities of amine, amide, and carboxyl groups present on $\mathrm{Cu}(\mathrm{II})-\mathrm{S}$. maxima surface were higher than for pristine microalga. Such results confirmed ionic interaction between these groups and metal cations, which was in accordance with the published literature [21].

On the other hand, affecting ion sorption by hydroxyl group, commonly considered as one of the major binding site on the biomass surface [21], could not be evaluated, since none of the obtained records represented this group only. There was a peak shift observed for all bands of $\mathrm{Cu}$ (II) loaded microalga, which were recognized as $-\mathrm{OH}$ bound vibration positions $\left(1,235.52,1,154.21\right.$, and $\left.1,049.80 \mathrm{~cm}^{-1}\right)$. Therefore, it was assumed that hydroxyl group interacted with metal ions and further investigation was performed to prove this statement (Section 3.4).

In case of $\mathrm{Cu}(\mathrm{II})$-Spirulina maxima spectrum, no band corresponding to neither phosphoryl ( $\equiv \mathrm{P}-\mathrm{O}-$ ) nor sulfone (in deprotonated form of sulfonate, $-\mathrm{SO}_{3}-$ ) groups was detected, as well. On the other hand, these valleys were detected for pristine Spirulina sp. and S. maxima at 862 and $830 \mathrm{~cm}^{-1}$, respectively. Since occurring of particular band depended on whether biomass was subjected to biosorption or not, surface group represented by this band should be involved in ion binding. Thus, it was concluded that metal cations were likely bound to Spirulina maxima biomass with phosphoryl and deprotonated sulfone, occurring mainly in sulfonated polysaccharides, group [35].

FTIR studies revealed that the surface composition of Spirulina sp. is similar to Spirulina maxima and thus comparable adsorptive properties would be expected. As a consequence, the same functional groups were considered to be affected by the presence of metal ions and responsible for their sorption.

The spectrophotometric records were confronted with potentiometric titration in order to complement the surface characteristics of Spirulina biomass, concerning both type and capacity of the major binding sites.

3.4. Potentiometric Titration of Biosorbent Surface. The validity of using the potentiometric titration to investigate the nature of biomass surface is based on a postulate that ion exchange between biomass binding sites and metal cation solution is the dominant mechanism of biosorption. The major functional groups involved in cation binding in the $\mathrm{pH}$ range 2-12 were identified, as well [20, 24]. In conducted research, potentiometric titration was performed to verify the results of FTIR analysis and provide detailed information on ion binding sites of Spirulina sp. and Spirulina maxima cell walls.

The experimental data from potentiometric titration were analyzed with three models, assuming the presence of one, two, and three types of functional groups on biomaterial surface, respectively [20]. Since the algal biomass has been shown to act as weakly acidic ion exchanger, the model of multiprotic acid might be used to characterize its titration curve. In order to improve model conformance with experimental conditions, modification considering different concentration of each surface functional group was introduced $[20,24]$. Elaborated model was expressed by a nonlinear correlation between molar ratio of added titrant $\left(x_{\text {add }}\right)$ and $\mathrm{pH}$ value, described with one of three equations presented in Michalak and Chojnacka report [24]. Evaluation of fitting particular model to the experimental results required estimating acidic dissociation constant $\left(K_{a}\right)$ values and heights 
TABLE 5: Surface functional groups and their concentration evaluated with potentiometric titrations.

\begin{tabular}{|c|c|c|c|c|}
\hline \multirow{3}{*}{ Functional group } & \multicolumn{4}{|c|}{ Microalga(e) } \\
\hline & \multicolumn{2}{|c|}{ Spirulina maxima } & \multicolumn{2}{|c|}{ Spirulina sp. } \\
\hline & $\mathrm{pK}_{a}$ & $\begin{array}{c}\text { Concentration } \\
\text { meq }^{-1}\end{array}$ & $\mathrm{pK}_{a}$ & $\begin{array}{c}\text { Concentration } \\
\text { meq g }^{-1}\end{array}$ \\
\hline Carboxyl & 2.66 & 2.99 & 2.77 & 0.998 \\
\hline Phosphoryl & 6.68 & 1.73 & 6.96 & 0.573 \\
\hline Amine or hydroxyl & 10.9 & 3.27 & 10.8 & 0.889 \\
\hline Total & & 7.99 & & 2.46 \\
\hline
\end{tabular}

of jumps (drop in $x_{\text {add }}$ ) observed in the titration curve, which were determined based on nonlinear regression and the first and the second derivative course using Mathematica v. 3.0 software (Wolfram; Hanborough, Oxfordshire, United Kingdom) $[20,24]$. In accordance with previous studies [15, $19,20,24,25]$, the model assuming three different types of ion binding groups was the best fitted to the results from Spirulina sp. and Spirulina maxima potentiometric titration. Thus modified model for triprotic acid was used to describe experimental data (see (4)) [20]:

$$
\begin{aligned}
X_{\mathrm{add}}= & \frac{a}{1+10^{-\mathrm{pH}} / K_{a 2}+10^{-2 \mathrm{pH}} /\left(K_{a 1} \cdot K_{a 2}\right)+10^{\mathrm{pH}} \cdot K_{a 3}} \\
& +\frac{2 \cdot b}{1+10^{-\mathrm{pH}} / K_{a 1}+10^{\mathrm{pH}} \cdot K_{a 2}+10^{2 \cdot \mathrm{pH}} \cdot K_{a 2} \cdot K_{a 3}} \\
& +(3 \cdot c)\left(1+10^{\mathrm{pH}} \cdot K_{a 1}+10^{2 \cdot \mathrm{pH}} \cdot K_{a 1} \cdot K_{a 2}\right. \\
& \left.+10^{3 \cdot \mathrm{pH}} \cdot K_{a 1} \cdot K_{a 2} \cdot K_{a 3}\right)^{-1} \cdot
\end{aligned}
$$

Model parameters $a, b$, and $c$ equate to heights of subsequent jumps in the regression curve and represent molar ratios of 1st, $2 \mathrm{nd}$, and 3rd identified functional group, respectively. According to the definition, the sum of molar ratios determined for individual components of the solution is always 1; thus, in proposed model above $a+b+c=1$. At the same time, the sum of jumps heights is equal to molar ratio of added titrant $\left(a+b+c=x_{\text {add }}\right)$. Considering both correlations, the solution of (4) is $x_{\text {add }}=1$.

The use of accepted model for a triprotic acid to describe potentiometric titration records gave a curve with three flex points (equivalence points of titration) [24], which was shown in Figure 8 along with the first and the second derivative course.

Acidity constants of binding sites on microalgae surface were evaluated from logarithmic measures, that is, $\mathrm{pK}_{a}$, which corresponded to zeros of the second derivative curve, calculated from the consecutive titration equivalence points [24]. Therefore, $\mathrm{pK}_{a}$ might be considered as specific $\mathrm{pH}$ value. In fact, $\mathrm{pK}_{a}$ determines such $\mathrm{pH}$, above which functional group of particular type are in the ionized form, mostly, and hence capable of exchanging $\mathrm{H}^{+}$with metal cations from the solution [20]. On the basis of determined $\mathrm{pK}_{a}$ values (black curve in Figure 8, Table 5), carboxyl, phosphoryl (phosphate, in particular) and either amine or hydroxyl groups [3639] were identified as ion binding sites present on both
Spirulina sp. and S. maxima cell walls. Obtained results were partially consentient with those from Fourier transform infrared analysis, besides $-\mathrm{OH}$, significance of which was not evident on IR spectra (Figure 7). The disparity between these two evaluations might be caused by conducting ion exchange at different $\mathrm{pH}$ values. Biosorption experiments preceding spectrophotometric assay were carried out at $\mathrm{pH} 5$, at which hydroxyl groups were not involved in cation binding due to their protonated form [20]. During potentiometric titration, solution $\mathrm{pH}$ exceeded $\mathrm{pK}_{a}$ enabling $-\mathrm{OH}$ to metal ion sorption.

On the other hand, potentiometric titration did not confirm involvement of sulfone group (as $-\mathrm{SO}_{3}-$ ) in cation exchange, while FTIR spectrometry proved otherwise. It was likely resulted from low sulfonate $\mathrm{pK}_{a}$ value, determined in the range of 1.0-2.5 [40], which was below the lowest $\mathrm{pK}_{a}$ estimated from the titration curve $-\mathrm{pK}_{a}=2.66$, assigned to carboxyl group. Since interaction of metal ions with deprotonated sulfone groups was evident on FTIR spectra, it might be concluded that $-\mathrm{SO}_{3}$ - occurred on the microalgal surface at insufficiently high concentration to be considered as the major binding site.

Based on FTIR records, capability of amide group to sorb cations was taken into consideration, as well. However, as opposed to $-\mathrm{SO}_{3}-$, neither peak shifting nor band intensity increase, noted after biosorption experiments, provided explicit information on interaction between surface amids groups and metal cations. Thus, involvement of $-\mathrm{NH}\left(2^{\circ}\right.$ amides) in ion exchange was verified with potentiometric titration by comparing amide $\mathrm{pK}_{a}$ to those evaluated based on model (4). None of obtained results corresponded to amides $\left(\mathrm{pK}_{a}=10.0\right)$ [41] and the highest value of determined experimentally $\mathrm{pK}_{a}$ was assigned to either amine or hydroxyl group $[15,20]$. Hence, it was claimed that amide groups did not act as binding sites or their capability to bind cations was not significant enough to be confirmed.

The concentrations of surface functional groups of each type were estimated from adequate molar ratio (height of jump) and cation exchange capacity ( $\left.q_{\text {cat. exch. }}\right)$ of the Spirulina biomass at the investigated $\mathrm{pH}$ range as follows:

$$
\begin{gathered}
q_{\text {cat. exch. }}=\frac{\mathrm{mEq}_{\text {biosorb. susp. }}^{\text {titrant }}-\mathrm{mEq}_{\text {blank }}^{\text {titrant }}}{m_{\text {biosorbent }}}, \\
{\left[q_{\text {cat. exch. }}\right]=\left[\mathrm{meq} \cdot \mathrm{g}^{-1}\right] .}
\end{gathered}
$$




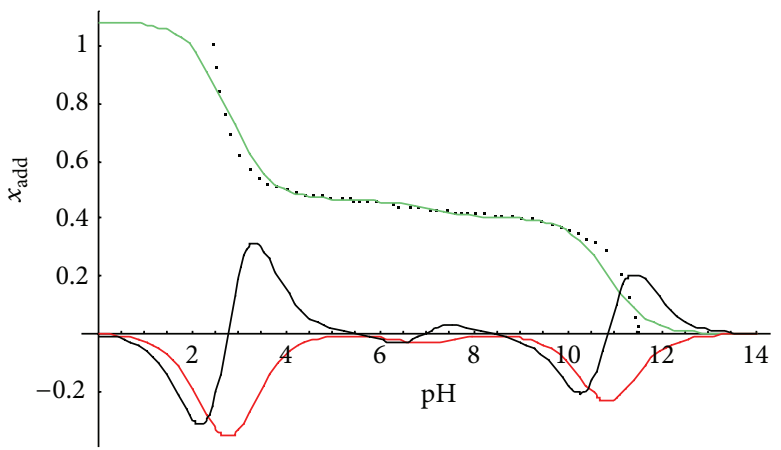

(a)

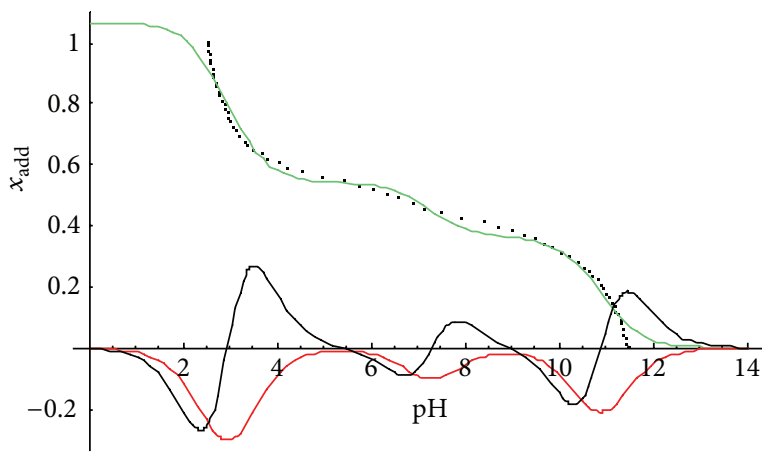

(b)

Figure 8: Potentiometric titration results of the Spirulina maxima (a) and Spirulina sp. (b) biomass samples. Green curve represents model curve describing the experimental data, red curve, the first derivative of the model curve, and black curve, the second derivative of the model curve.

Cation exchange capacity is an experimentally evaluated parameter, which defines capability of solid phase (sorbent) treated with an ion solution to replace surface-bound ion by another [42]. In practice, $q_{\text {cat. exch. }}$ is proportional to the quantity of standardized solution (acid or base) added per unit of biosorbent mass, during entire titration [24]. The use of titrant was calculated from a difference between amounts consumed by biomass suspension and blank sample (pure water $)$, expressed in units of milliequivalance $\left(\left[\mathrm{mEq}_{\text {sample }}^{\text {titrant }}\right]=\right.$ [meq]).

There were three jumps noted in both potentiometric titration curves obtained in the test (green lines in Figure 8). Each of jumps corresponded to specific functional group, $\mathrm{pK}_{a}$ value of which equated to flex point occurred in the jump line [24]. Hence, the concentration of particular binding site, $C_{\text {carboxyl }}, C_{\text {phosphoryl }}, C_{\text {amine/hydroxyl }}$, exposed on Spirulina cell surface was determined with equations (6), (7), and (8), respectively:

$$
\begin{gathered}
C_{\text {carboxyl }}=a \cdot q_{\text {cat. exch. }}, \\
C_{\text {phosphoryl }}=b \cdot q_{\text {cat. exch. }}, \\
C_{\text {amine } / \text { hydroxyl }}=c \cdot q_{\text {cat. exch.' }}, \\
{\left[C_{\text {functional group }}\right]=\left[\mathrm{meq} \cdot \mathrm{g}^{-1}\right] .}
\end{gathered}
$$

The results of the functional group concentrations, as well as total content of identified binding sites, for both Spirulina biomasses were shown in Table 5 .

Despite the same type of groups capable of cation exchange, microalgae biosorbents differed in the incidence of binding sites on the cell wall. Spirulina maxima surface was characterized by 3.0 and 3.7 times higher content of both $-\mathrm{COO}$ and $\equiv \mathrm{P}-\mathrm{O}-$, and $-\mathrm{NH}_{3} /-\mathrm{OH}$, respectively, compared to Spirulina sp. Literature reported that surface composition and, thus, adsorptive properties of biomass depend on its species and condition of growth [20]. Previous studies on Spirulina sp. in four different morphological types proved that environmental condition manipulating affected the quality of biosorbent and, as a result, the efficacy of ion exchange
[20]. Comparing two biosorbents in terms of surface composition, only, identical treatment during whole investigation is required. Since no detailed information was known on Spirulina sp. cultivation, conducted tests could not be considered as comparable. The aim of our own experiments was to confirm the applicability of both microalgae to microelement sorption, as well as to verify whether proposed conditions of culture growth provided material which is equally good with commercial product. Obtained results showed that Spirulina maxima grown under laboratory conditions would be more efficient biosorbent than lyophilized Spirulina sp. purchased on a market, due to a higher number of binding sites.

Evident disparities in the content of surface functional groups were proved; however, a few similarities between Spirulina sp. and S. maxima records were observed, as well. In case of both microalgae, the determined concentrations of carboxyl and either amine or hydroxyl groups were 1,5-1,9 times higher compared to the content of phosphoryl group. Such results might be caused by a different amount of compounds, from which these groups were derived. Since algal cell wall is built with polysaccharides, at most [43], diversity of these components influences the structure of binding sites exposed on the biomass surface. Hence, obtained composition of surface functional groups is specific for particular biosorbent species, which is in accordance with "fingerprint" theory of FTIR spectra. Similarity of the concentration ratios between each pair of identified groups $([-\mathrm{COO}]:[\equiv \mathrm{P}-\mathrm{O}-]$, $[-\mathrm{COO}]:\left[-\mathrm{NH}_{3}\right]$ or $[-\mathrm{OH}],[\equiv \mathrm{P}-\mathrm{O}-]:\left[-\mathrm{NH}_{3}\right]$ or $\left.[-\mathrm{OH}]\right)$ was likely resulted from close morphological resemblance between examined algae.

Although on S. maxima surface either amine or hydroxyl groups were mostly exposed, the carboxyl groups were considered to act as the major binding sites of both microalga. As carboxyl groups had the $\mathrm{pK}_{a}$ value of a little over 2.5 (the endpoint of titration), they were in the form of carboxylate ions capable of cation exchange within almost whole range of $\mathrm{pH}$, at which potentiometric titration was performed [20]. Moreover, deprotonation of binding sites, which made them available to metal ions, was enhanced along with $\mathrm{pH}$ increase. In case of titration curve, it might be concluded that higher $\mathrm{pH}$ improved the effectiveness of cation exchange. 


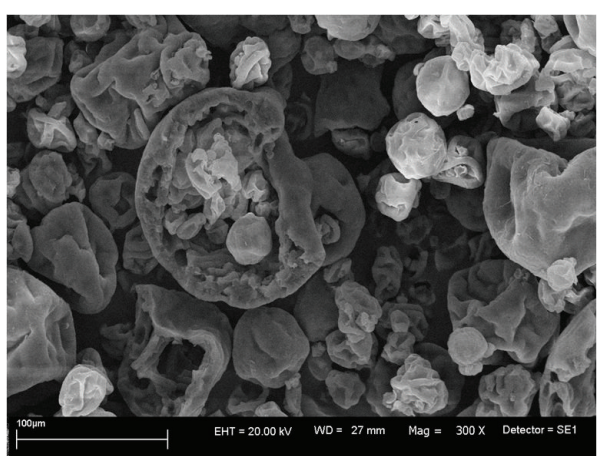

(a)

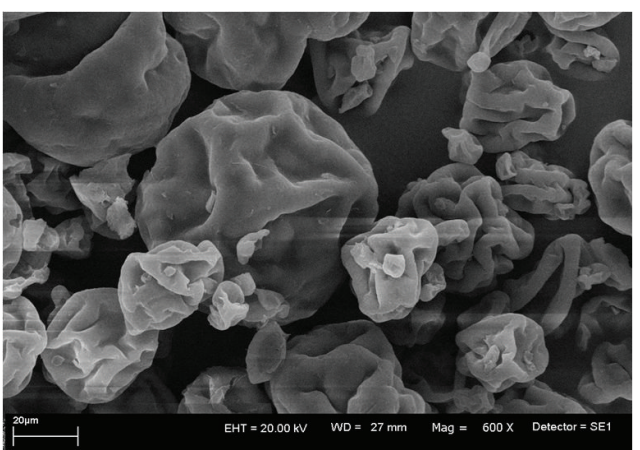

(b)

FIGURE 9: Images of lyophilized Spirulina sp. obtained with scanning electron microscope (SEM).

3.5. SEM-EDX Analysis of Algal Biomass Surface Enriched in Microelements. Previously conducted analysis enabled characterization of both type and capacity of binding sites present on Spirulina cell wall. However, neither FTIR spectroscopy nor potentiometric titration provided information on changes in elemental composition of microalgae surface, resulted from metal ion biosorption. Therefore, scanning electron microscopy with an energy dispersive X-ray analytical system technique was carried out to compare the concentration of elements on natural and cation-loaded microalgae cell wall. Since the same functional groups involved in ion exchange were proved to occur on both Spirulina sp. and S. maxima surface, it was decided to perform SEM-EDX assay with one of them only. For further, multi-elemental analysis lyophilized Spirulina sp. was selected. Although ion exchange capacity of $S$. maxima was proved to be over 3 times higher, commercial microalgae had certain quality, which provided reliable records. Moreover, Spirulina sp. was used as biosorbent in previous tests for exploring the biosorption mechanism $[15,20]$ and thus comparison of the results could be made.

SEM-EDX analysis was used in several studies to evaluate sorption of microelement cations onto seaweeds biomass $[25,27]$. Since studies on macroalgae proved this technique as suitable for investigating feed supplementation via biosorption, it was decided to apply SEM-EDX analytical system in present work.

The assay was preceded by biosorption experiments, performed in both single- and multimetal $\mathrm{Co}^{2+}, \mathrm{Cu}^{2+}$, $\mathrm{Mn}^{2+}, \mathrm{Zn}^{2+}$ ) system and under the specified conditions (Section 2.4). The surface composition of the microalgae samples loaded with each metal ion, in total of five, and all cations at once were analyzed and compared to the results for natural Spirulina sp. The photographs of the surface structure of pristine Spirulina sp. lyophilisate were taken with scanning electron microscopy and shown in Figure 9.

The samples of treated and nontreated biomass were subjected to elemental analysis using EDX system and six distinct X-ray spectra were obtained (Figure 10).

The results obtained from EDX analysis showed that each of examined Spirulina samples gave different set of bands due to changes in the surface composition, caused by biomass treatment with cation(s) in single- or multimetal system. On the spectra of microalgae enriched in $\mathrm{Co}(\mathrm{II}), \mathrm{Cu}(\mathrm{II}), \mathrm{Mn}(\mathrm{II})$, $\mathrm{Zn}$ (II) ions, and all of them together, the bands representing overbalanced concentration of these cations were observed in Figures 10(b)-10(f), respectively, while there were no corresponding bands recorded on the natural biomass spectrum (Figure 10(a)). Diversity of the cell wall composition among loaded Spirulina samples was noted, as well. Previous studies [20] proved that efficiency, with which surface functional groups bound ions varied depending on particular element (metal). The affinity of biosorbent for sorbate is specific and attributable to both the type and valence of ion and $\mathrm{pK}_{a}$ value of the binding functional group. Thus, this parameter needs to be separately verified for each system. In present research, a relative affinity between Spirulina sp. and Co(II), $\mathrm{Cu}(\mathrm{II}), \mathrm{Mn}(\mathrm{II})$, and $\mathrm{Zn}$ (II) ions was determined based on SEM-EDX results, by comparing the concentration of the one type of bound ion to other records. The summary of element concentration evaluated for pristine Spirulina and samples after biosorption experiments was presented in Table 6 .

The results obtained during X-ray exams on cationloaded Spirulina sp. showed increased content of all microelement ions, in which biomass was enriched via biosorption. For single-metal system, the concentration of $\mathrm{Co}(\mathrm{II}), \mathrm{Cu}(\mathrm{II})$, $\mathrm{Mn}(\mathrm{II})$, and $\mathrm{Zn}$ (II) was about $12,71.5,1,380$, and over 1,760 times higher, respectively, compared to natural microalgae, while experiment in multicomponent system gave an increase of the same cations at $14.5,22,87$, and over 180 times. (The increase of zinc ion concentration was determined as the ratio of the corresponding result for $\mathrm{Zn}$ (II)-enriched Spirulina sp., in either single-or multimetal system, to the lower detection limit of EDX system.) Although, performing biosorption in multimetal system was less effective, it provided supplementation with all examined ions, at once. Thus, making a decision concerning more preferable method of enrichment Spirulina with cation(s) depends on the application, to which the loaded algal biomass is intended.

Analysis of the surface composition of various elements justified the relevance to perform parallel biosorption experiments in single- and multimetal system, since the presence of competing cations significantly affected the binding preferences of biomass. Disparities in absolute concentration of 


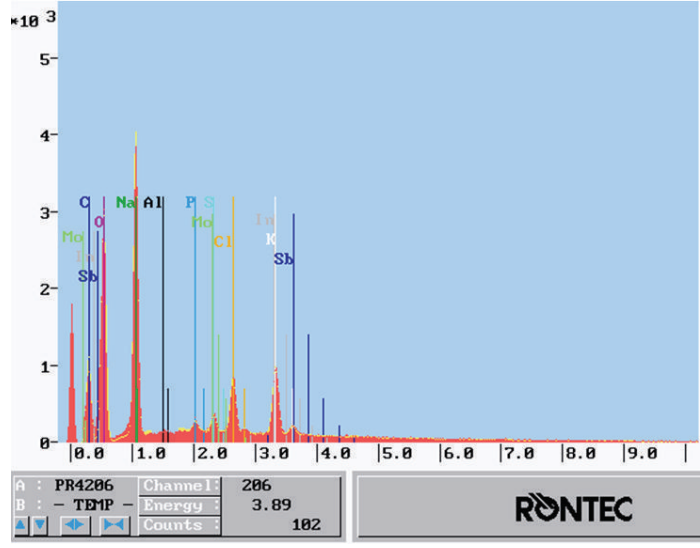

(a)

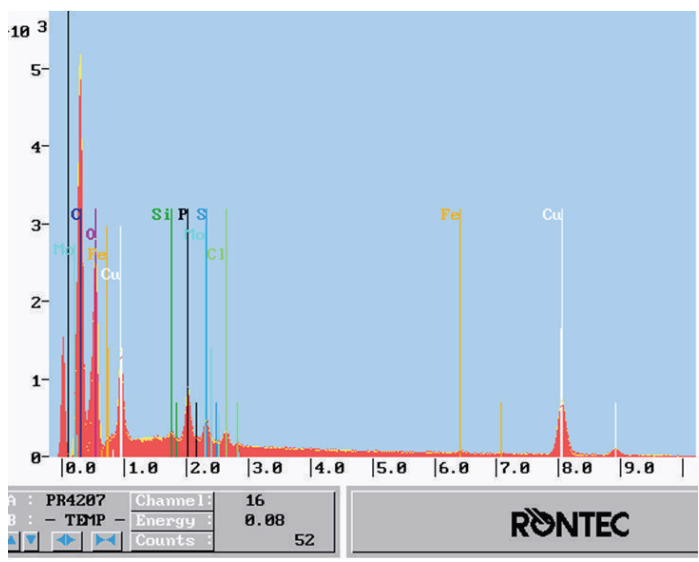

(c)

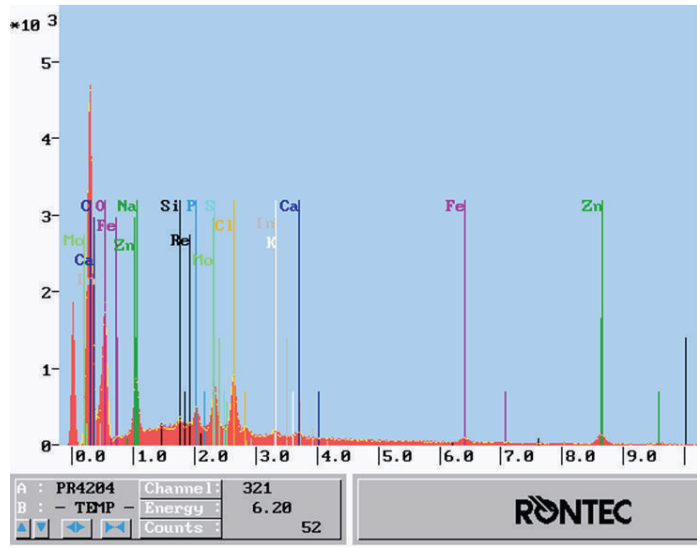

(e)

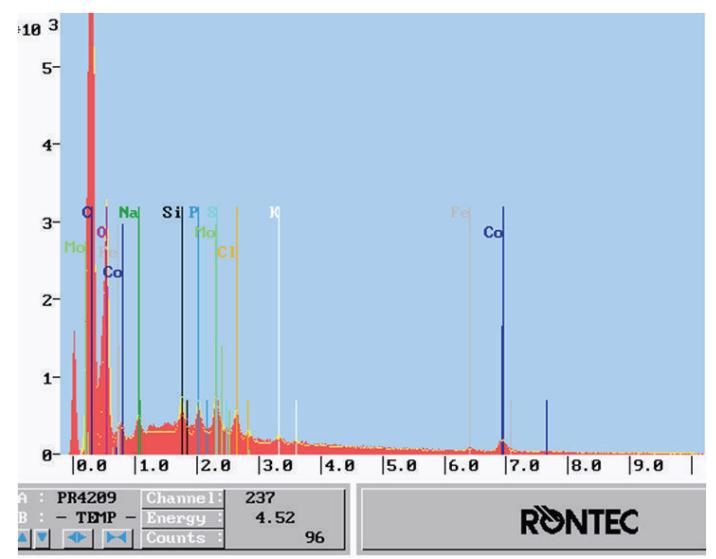

(b)

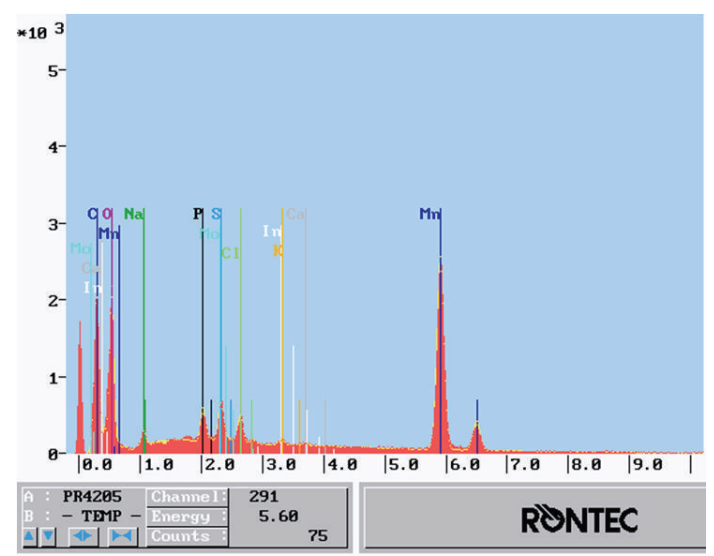

(d)

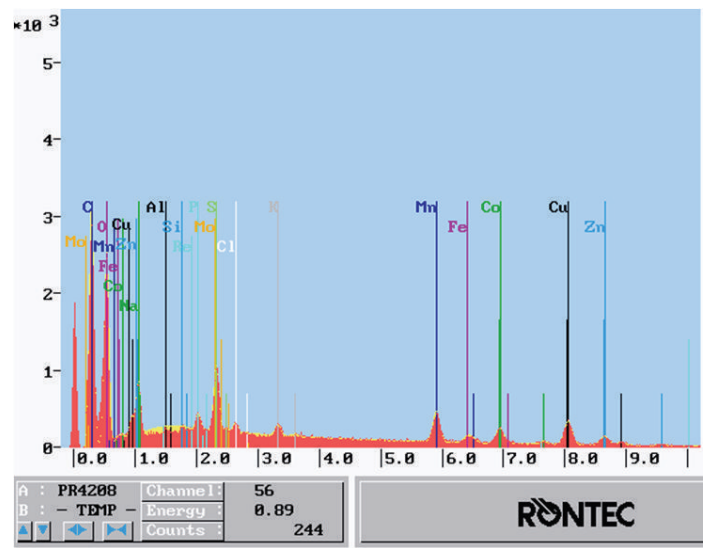

(f)

FIGURE 10: X-ray spectrum, mineral trace analysis of Spirulina sp. surface. (a) pristine microalgae biomass; Spirulina sp. enriched in (b) Co(II) ions, (c) $\mathrm{Cu}(\mathrm{II})$ ions, (d) $\mathrm{Mn}$ (II) ions, and (e) $\mathrm{Zn}$ (II) ions; (f) Spirulina sp. enriched in all Co(II), $\mathrm{Cu}(\mathrm{II}), \mathrm{Mn}(\mathrm{II})$, and $\mathrm{Zn}$ (II) ions.

each microelement and the efficacy of its interacting with surface functional groups, compared to other elements, were noted. The Spirulina sp. affinity for examined metal ions in single- and multicomponent system fallowed $\mathrm{Mn}(\mathrm{II})>$ $\mathrm{Cu}(\mathrm{II})>\mathrm{Zn}(\mathrm{II})>\mathrm{Co}(\mathrm{II})$ and $\mathrm{Cu}(\mathrm{II})>\mathrm{Mn}(\mathrm{II})>\mathrm{Co}(\mathrm{II})>$ $\mathrm{Zn}(\mathrm{II})$, respectively. The concentration difference between the most and the least easily bound cation was 10 times higher in case of samples prepared in single-metal system than in the presence of competing ions. As all cations were equally charged and biosorption experiments were carried out using the same biosorbent species, it was concluded that interaction, and hence affinity, between biomass of Spirulina sp. and each microelement cation depended on sorbate type(s), only. 
TABLE 6: Atomic concentration of elements present on the surface of pristine and metal cation-loaded Spirulina sp., assessed according to the analysis of X-ray spectrum.

\begin{tabular}{|c|c|c|c|c|c|c|c|}
\hline \multirow{2}{*}{ Element } & \multicolumn{6}{|c|}{ Atomic concentration of elements, $\%$ of all detected ions } & \multirow{2}{*}{ Detection limits, \% } \\
\hline & Natural biomass & Co-Spirulina sp. & $\mathrm{Cu}-$ Spirulina sp. & $\begin{array}{l}\text { Mn-Spirulina } \\
\text { sp. }\end{array}$ & Zn-Spirulina sp. & $\begin{array}{c}\mathrm{Co}, \mathrm{Cu}, \mathrm{Mn}, \\
\text { Zn-Spirulina sp. }\end{array}$ & \\
\hline \multicolumn{8}{|l|}{ * } \\
\hline $\mathrm{C}$ & $17.9 \pm 4.86$ & $54.8 \pm 8.99$ & $44.7 \pm 7.94$ & $25.6 \pm 2.23$ & $47.9 \pm 8.89$ & $33.7 \pm 6.81$ & $0.277-100$ \\
\hline $\mathrm{Cl}$ & $1.80 \pm 0.12$ & $0.71 \pm 0.08$ & $0.42 \pm 0.07$ & $1.60 \pm 0.16$ & $2.0 \pm 0.13$ & $0.20 \pm 0.05$ & $0.001-2.621$ \\
\hline $\mathrm{O}$ & $59.31 \pm 11.2$ & $39.4 \pm 6.76$ & $42.9 \pm 7.67$ & $38.3 \pm 3.31$ & $42.8 \pm 8.24$ & $54.9 \pm 10.14$ & $0.525-100$ \\
\hline $\mathrm{P}$ & $0.26 \pm 0.06$ & $0.69 \pm 0.06$ & $1.37 \pm 0.09$ & $1.73 \pm 0.13$ & $0.69 \pm 0.07$ & $0.29 \pm 0.05$ & $0.001-2.013$ \\
\hline$S$ & $0.49 \pm 0.07$ & $0.00 \pm 0.00$ & $0.35 \pm 0.07$ & $1.37 \pm 0.16$ & $0.86 \pm 0.09$ & $1.36 \pm 0.09$ & $0.001-2.307$ \\
\hline \multicolumn{8}{|l|}{$* *$} \\
\hline Co & $0.08 \pm 0.08$ & $0.95 \pm 0.13$ & $<\mathrm{LLD}$ & $<\mathrm{LLD}$ & $<\mathrm{LLD}$ & $1.16 \pm 0.15$ & $0.076-6.924$ \\
\hline $\mathrm{Cu}$ & $0.13 \pm 0.11$ & $<\mathrm{LLD}$ & $9.27 \pm 0.69$ & $<\mathrm{LLD}$ & $<\mathrm{LLD}$ & $2.85 \pm 0.30$ & $0.083-8.040$ \\
\hline $\mathrm{Fe}$ & $0.05 \pm 0.06$ & $0.15 \pm 0.09$ & $0.15 \pm 0.09$ & $<\mathrm{LLD}$ & $0.41 \pm 0.10$ & $0.36 \pm 0.10$ & $0.060-6.398$ \\
\hline $\mathrm{Mn}$ & $0.02 \pm 0.00$ & $<\mathrm{LLD}$ & $<\mathrm{LLD}$ & $27.6 \pm 1.27$ & $<\mathrm{LLD}$ & $1.74 \pm 0.15$ & $0.063-5.894$ \\
\hline $\mathrm{Zn}$ & $<$ LLD & $<$ LLD & $<$ LLD & $<\mathrm{LLD}$ & $1.76 \pm 0.31$ & $0.18 \pm 0.26$ & $0.001-8.630$ \\
\hline \multicolumn{8}{|l|}{$* * *$} \\
\hline $\mathrm{Ca}$ & $0.12 \pm 0.06$ & $<\mathrm{LLD}$ & $<\mathrm{LLD}$ & $0.17 \pm 0.11$ & $0.19 \pm 0.07$ & $<\mathrm{LLD}$ & $0.341-3.690$ \\
\hline $\mathrm{K}$ & $2.58 \pm 0.18$ & $0.22 \pm 0.06$ & $<\mathrm{LLD}$ & $0.08 \pm 0.09$ & $0.00 \pm 0.01$ & $0.28 \pm 0.07$ & $0.001-3.312$ \\
\hline $\mathrm{Na}$ & $12.5 \pm 0.85$ & $0.42 \pm 0.05$ & $<$ LLD & $1.09 \pm 0.19$ & $1.01 \pm 0.11$ & $1.60 \pm 0.13$ & $0.001-1.041$ \\
\hline
\end{tabular}

${ }^{*}$ macroelements, ${ }^{* *}$ microelements, ${ }^{* * *}$ alkali, and alkaline earth metals.

$<$ LLD: lower limit of detection.

Apart from increased concentration of cobalt, copper, manganese, and/or zinc, the surface composition of loaded microalgae showed significantly lower content of alkali metal compared to natural cells. Such results might be referred to as ion exchange mechanism, via which biosorption primarily occurs $[35,44]$. The difference of sodium concentration before and after biomass enrichment was more evident than in the case of potassium; thus $\mathrm{Na}(\mathrm{I})$ was claimed to be most involved in ion exchanging among cations naturally bound with surface functional groups. Both sodium and potassium ions interacted with all examined sorbates. According to the literature, alkaline earth metal ions might also participate in biosorption $[35,44]$, which was confirmed in present work, since the concentration of calcium cations decreased due to loading Spirulina sp. with microelement(s). However, as opposed to $\mathrm{Na}(\mathrm{I})$ and $\mathrm{K}(\mathrm{I})$, exchanging $\mathrm{Ca}(\mathrm{II})$ with other metal ions was noted in the presence of $\mathrm{Co}(\mathrm{II})$ and $\mathrm{Cu}(\mathrm{II})$ cations and in multicomponent system, only.

The composition of microalgae surface, besides ions exchanged during biosorption, contained elements, such as cell wall building blocks (e.g., carbon) or functional group constituents (e.g., phosphorus), the concentration of which should not have varied after microelement ion binding, while it did. Disparities in records for natural and enriched Spirulina sp. were likely observed due to conformational changes of neighboring functional groups, as they interacted with different cations. According to posited mechanism of biosorption-ion exchange, cation binding onto biosorbent occurs through electron donor-acceptor interactions, resulting in a replacement of naturally bound ions: $\mathrm{Na}(\mathrm{I}), \mathrm{K}(\mathrm{I})$, and/or $\mathrm{Ca}(\mathrm{II})$. Both alkali and alkaline earth metal ions are larger in size compared to microelement cations used for biosorption experiments. The ionic radius for $\mathrm{Na}(\mathrm{I}), \mathrm{K}(\mathrm{I})$, and $\mathrm{Ca}(\mathrm{II})$ is $95 \mathrm{pm}, 133 \mathrm{pm}$, and $99 \mathrm{pm}$, respectively; in contrast, ionic radius for $\mathrm{Co}(\mathrm{II}), \mathrm{Cu}(\mathrm{II}), \mathrm{Mn}(\mathrm{II})$, and $\mathrm{Zn}$ (II) is in the range of $73-80 \mathrm{pm}[45,46]$. The exchange of larger cations to smaller cations affects the spatial distribution of ions onto the biosorbent surface and either revealing or concealing the particular elements on Spirulina sp. surface might be observed as increase or decrease of the corresponding bands in the X-ray spectra.

3.6. Comparison of SEM-EDX and ICP-OES Techniques. Inductively coupled plasma-optical emission spectrometry was used in several studies as the suitable method for investigating the elemental composition of biosorbent surface, thus assessing the mechanism of the process and applicability of the biomass to binding particular ions $[25,26]$. Since ICP-OES gave reliable and explicit results from previous experiments with Spirulina $[15-17,20]$, it was decided to employ this technique to verify the records from SEM-EDX analysis, in present work. However, there was no cation exchanged during biosorption, the atomic concentration of which was evaluated in all examined samples. Thus, the correlation coefficient between ICP-OES and SEM-EDX analytical techniques was assessed on the example of the results obtained for sodium ion, as it was most frequently replaced by microelement cations regardless of the system tested. The ratios of $\mathrm{Na}(\mathrm{I})$ concentration on natural and loaded Spirulina surface, determined by both compared analysis, were depicted graphically and linear regression equation was determined (Figure 11). Records for microalga loaded with 


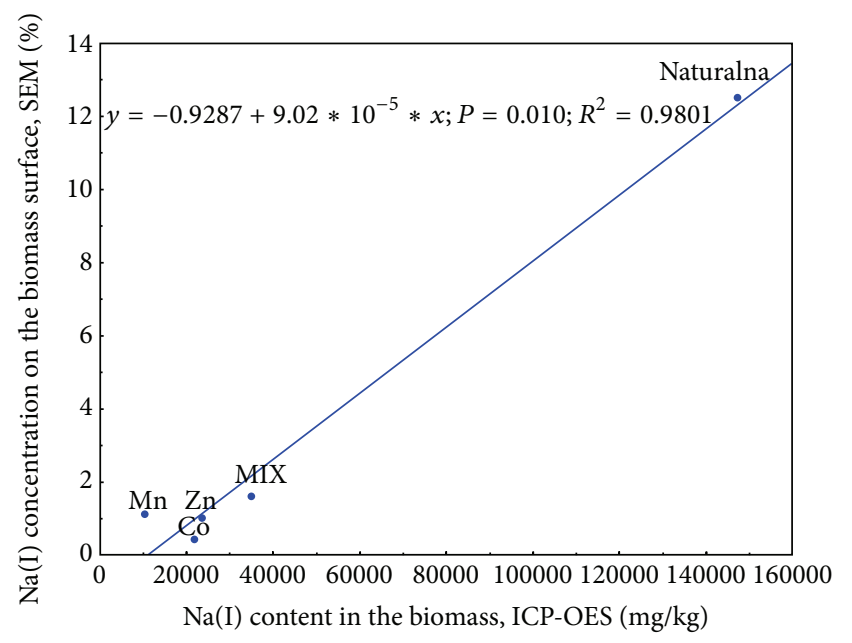

FIGURE 11: Correlation between the concentration of $\mathrm{Na}$ (I) ions on Spirulina sp. surface, assessed by ICP-OES and SEM-EDX analysis. Naturalna-pristine microalgae; Co, Mn, Zn-biomass enriched in $\mathrm{Co}(\mathrm{II}), \mathrm{Mn}(\mathrm{II})$ and $\mathrm{Zn}$ (II) cations, respectively; MIX-biomass enriched in metal cations in multi-component system. Values on the $x$ and $y$ axis indicate $\mathrm{Na}(\mathrm{I})$ concentration determined by ICP-OES and EDX and analytical system, respectively.

$\mathrm{Cu}(\mathrm{II})$ were not involved in estimating the ICP-OEC/SEMEDX correlation coefficient, since the content of sodium ions was under detection limit of X-ray system.

Due to comparison between ICP-OES and SEM-EDX analysis, relatively high value of the correlation coefficient was achieved $\left(R^{2}=0.9891\right)$. $R$-squared value close to 1 confirmed both techniques to give the similar results of surface elemental composition and thus to be equally useful in biosorption investigations.

\section{Conclusions}

Biosorption of microelement ions: copper, cobalt, zinc, and manganese, from aqueous solutions by Spirulina biomass was investigated to assess the applicability of enriched algae as a feed supplement for livestock. Parallel experiments in single- and multicomponent system were performed. In present work, adsorptive properties of cultivated under laboratory conditions Spirulina maxima were verified by comparing to commercially available, lyophilized Spirulina sp. Both examined biosorbents were proved to increase. The results obtained from potentiometric titration showed that higher $\mathrm{pH}$ value favored metal ions biosorption, since more binding sites were deprotonated. Thereby, ion exchange was confirmed as the dominant mechanism of the process. Although, biosorption capacity was over 3 times higher for $S$. maxima than commercial lyophilisate, loading Spirulina sp. with microelement ions increased their surface concentration from 12 up to 1,760 times. The affinity of biomass for microelement cations, determined on the example of pristine and loaded Spirulina sp., in single- and multicomponent system was $\mathrm{Mn}(\mathrm{II})>\mathrm{Cu}(\mathrm{II})>\mathrm{Zn}(\mathrm{II})>\mathrm{Co}(\mathrm{II})$ and $\mathrm{Cu}(\mathrm{II})>$ $\mathrm{Mn}(\mathrm{II})>\mathrm{Co}(\mathrm{II})>\mathrm{Zn}(\mathrm{II})$, respectively. FTIR analysis showed similar chelating characteristics of metal coordination groups to results evaluated with titration. The binding sites present on Spirulina cell wall included carboxyl, phosphoryl, and either hydroxyl or amine groups. Sulfonate groups were also proved to participate in ion sorption (FTIR spectra). The concentration of elements on the surface of natural and metal ion-loaded biomass was assessed by both ICP-OES and SEMEDX techniques. Since relatively high value of correlation coefficient was shown between these systems, usefulness of SEM-EDX analysis in biosorption studies on Spirulina biomass was confirmed, as well.

\section{Conflict of Interests}

The authors declare that there is no conflict of interests regarding the publication of this paper.

\section{Acknowledgments}

The work was financially supported by Polish National Centre for Research and Development-Project no. N R05 0014 10 and Grant entitled: "Innovative technology of seaweed extracts: components of fertilizers, feeds, and cosmetics"Project no. PBS/1/A1/2/2012 and National Science CentreProject no. 2012/05/E/ST8/03055. The work was financially supported by Polish National Science Centre-Project no. UMO-2012/05/E/ST8/03055.

\section{References}

[1] R. Gupta, P. Ahuja, S. Khan, R. K. Saxena, and H. Mohapatra, "Microbial biosorbents: meeting challenges of heavy metal pollution in aqueous solutions," Current Science, vol. 78, no. 8, pp. 967-973, 2000.

[2] Y. Liu and Y.-J. Liu, "Biosorption isotherms, kinetics and thermodynamics," Separation and Purification Technology, vol. 61, no. 3, pp. 229-242, 2008.

[3] R. Vannela and S. K. Verma, " $\mathrm{Cu}^{2+}$ removal and recovery by SpiSORB: batch stirred and up-flow packed bed columnar reactor systems," Bioprocess and Biosystems Engineering, vol. 29, no. 1, pp. 7-17, 2006.

[4] H. Chen and S.-S. Pan, "Bioremediation potential of spirulina: toxicity and biosorption studies of lead," Journal of Zhejiang University: Science, vol. 6, no. 3, pp. 171-174, 2005.

[5] A. G. Murugesan, S. Maheswari, and G. Bagirath, "Biosorption of cadmium by live and immobilized cells of Spirulina platensis," International Journal of Environmental Research, vol. 2, no. 3, pp. 307-312, 2008.

[6] E. Finocchio, A. Lodi, C. Solisio, and A. Converti, "Chromium (VI) removal by methylated biomass of Spirulina platensis: the effect of methylation process," Chemical Engineering Journal, vol. 156, no. 2, pp. 264-269, 2010.

[7] C. D. Magro, M. C. Deon, A. D. Rossi, C. O. Reinehr, M. Hemkemeier, and L. M. Colla, "Chromium (VI) biosorption and removal of chemical oxygen demand by Spirulina platensis from waste water-supplemented culture medium," Journal of Environmental Science and Health A: Toxic/Hazardous Substances and Environmental Engineering, vol. 47, no. 12, pp. 18181824, 2012. 
[8] C. Solisio, A. Lodi, and E. Finocchio, "Effects of $\mathrm{pH}$ on chromate(VI) adsorption by Spirulina platensis biomass: batch tests and FT-IR studies," Water Science and Technology, vol. 67, no. 9, pp. 1916-1922, 2013.

[9] O. Murali and S. K. Mehar, "Bioremediation of heavy metals using Spirulina," International Journal of Geology, Earth and Environmental Sciences, vol. 4, no. 1, pp. 244-249, 2014.

[10] K. Chojnacka, A. Chojnacki, and H. Górecka, “Trace element removal by Spirulina sp. from copper smelter and refinery effluents," Hydrometallurgy, vol. 73, no. 1-2, pp. 147-153, 2004.

[11] P. G. Hiremath and P. Binnal, "First report on biosorption of fluoride on the microalga Spirulina platensis: batch studies," Asian-American Journal of Chemistry, vol. 1, no. 1, pp. 1-10, 2013.

[12] H. Doshi, A. Ray, and I. L. Kothari, "Live and dead Spirulina sp. to remove arsenic (v) from water," International Journal of Phytoremediation, vol. 11, no. 1, pp. 53-64, 2009.

[13] G. L. Dotto, V. M. Esquerdo, M. L. G. Vieira, and L. A. A. Pinto, "Optimization and kinetic analysis of food dyes biosorption by Spirulina platensis," Colloids and Surfaces B: Biointerfaces, vol. 91, no. 1, pp. 234-241, 2012.

[14] I. Priyadarshani, D. Sahu, and B. Rath, "Microalgal bioremediation: current practices and perspectives," Journal of Biochemical Technology, vol. 3, no. 3, pp. 299-304, 2011.

[15] A. Zieliñska and K. Chojnacka, "The comparison of biosorption of nutritionally significant minerals in single- and multimineral systems by the edible microalga Spirulina sp," Journal of the Science of Food and Agriculture, vol. 89, no. 13, pp. 22922301, 2009.

[16] A. Saeid, K. Chojnacka, M. Korczyński, D. Korniewicz, and Z. Dobrzański, "Biomass of Spirulina maxima enriched by biosorption process as a new feed supplement for swine," Journal of Applied Phycology, vol. 25, no. 2, pp. 667-675, 2013.

[17] A. Saeid, K. Chojnacka, M. Korczyński, D. Korniewicz, and Z. Dobrzański, "Effect on supplementation of Spirulina maxima enriched with $\mathrm{Cu}$ on production performance, metabolical and physiological parameters in fattening pigs," Journal of Applied Phycology, vol. 25, no. 5, pp. 1607-1617, 2013.

[18] I. Zinicovscaia, G. Duca, V. Rudic et al., "Spirulina platensis as biosorbent of zinc in water," Environmental Engineering and Management Journal, vol. 12, no. 5, pp. 1079-1084, 2013.

[19] S. Schiewer and B. Volesky, "Modeling multi-metal ion exchange in biosorption," Environmental Science and Technology, vol. 30, no. 10, pp. 2921-2927, 1996.

[20] K. Chojnacka, A. Chojnacki, and H. Górecka, "Biosorption of $\mathrm{Cr}^{3+}, \mathrm{Cd}^{2+}$ and $\mathrm{Cu}^{2+}$ ions by blue-green algae Spirulina sp.: kinetics, equilibrium and the mechanism of the process," Chemosphere, vol. 59, no. 1, pp. 75-84, 2005.

[21] K. Chojnacka, "Biosorption," in Biosorption and Bioaccumulation in Practice, chapter 2.2, pp. 5-15, Nova Science Publishers, New York, NY, USA, 2009.

[22] U. G. Schlösser, "Sammlung von algenkulturen," Berichte der Deutschen Botanischen Gesellschaft, vol. 95, no. 1, pp. 181-276, 1982.

[23] A. Vonshak, "Spirulina: growth, physiology and biochemistry," in Spirulina Platensis (Arthrospira): Physiology, Cell-Biology and Biotechnology, chapter 3, pp. 43-66, Taylor \& Francis, London, UK, 1997.

[24] I. Michalak and K. Chojnacka, "Interactions of metal cations with anionic groups on the cell wall of the macroalga Vaucheria sp," Engineering in Life Sciences, vol. 10, no. 3, pp. 209-217, 2010.
[25] I. Michalak, K. Chojnacka, and K. Marycz, "Using ICP-OES and SEM-EDX in biosorption studies," Microchimica Acta, vol. 172, no. 1, pp. 65-74, 2011.

[26] K. Chojnacka, "The application of multielemental analysis in the elaboration of technology of mineral feed additives based on Lemna minor biomass," Talanta, vol. 70, no. 5, pp. 966-972, 2006.

[27] I. Michalak, K. Chojnacka, and A. Witek-Krowiak, "State of the art for the biosorption process-a review," Applied Biochemistry and Biotechnology, vol. 170, no. 6, pp. 1389-1416, 2013.

[28] A. B. Dekhil, Y. Hannachi, A. Ghorbel, and T. Boubaker, "Removal of lead and cadmium ions from aqueous solutions using the macroalga Caulerpa racemosa," Chemistry and Ecology, vol. 27, no. 3, pp. 221-234, 2011.

[29] W. H. Fan, Z. Z. Xu, and Q. Li, "Kinetics and mechanism of nickel(II) ion biosorption by immobilized brown Laminaria japonica algae," Adsorption Science and Technology, vol. 28, no. 6, pp. 499-507, 2010.

[30] S. S. Bozkurt, Z. B. Molu, L. Cavas, and M. Merdivan, "Biosorption of uranium (VI) and thorium (IV) onto Ulva gigantea (Kützing) bliding: discussion of adsorption isotherms, kinetics and thermodynamic," Journal of Radioanalytical and Nuclear Chemistry, vol. 288, no. 3, pp. 867-874, 2011.

[31] J. Plaza Cazón, M. Viera, S. Sala, and E. Donati, "Biochemical characterization of Macrocystis pyrifera and Undaria pinnatifida (Phaeophyceae) in relation to their potentiality as biosorbents," Phycologia, vol. 53, no. 1, pp. 100-108, 2014.

[32] R. Davis and L. J. Mauer, "Fourier tansform infrared (FT-IR) spectroscopy: a rapid tool for detection and analysis of foodborne pathogenic bacteria," in Current Research, Technology and Education Topics in Applied Microbiology and Microbial Biotechnology, vol. 2 of Microbiology Series, pp. 1582-1594, FORMATEX, Badajoz, Spain, 2010.

[33] S. Venkatesan, K. Pugazhendy, D. Sangeetha, C. Vasantharaja, S. Prabakaran, and M. Meenambal, "Fourier transform infrared (FT-IR) spectoroscopic analysis of Spirulina," International Journal of Pharmaceutical \& Biological Archives, vol. 3, no. 4, pp. 969-972, 2012.

[34] P. Prabakaran and A. D. Ravindran, "Efficacy of different extraction methods of phycocyanin from Spirulina platensis," International Journal of Research in Pharmacy and Life Sciences, vol. 1, no. 1, pp. 15-20, 2013.

[35] E. Fourest, C. Canal, and J.-C. Roux, "Improvement of heavy metal biosorption by mycelial dead biomasses (Rhizopus arrhizus, Mucor miehei and Penicillium chrysogenum): $\mathrm{pH}$ control and cationic activation," FEMS Microbiology Reviews, vol. 14, no. 4, pp. 325-332, 1994.

[36] J. S. Cox, D. S. Smith, L. A. Warren, and F. G. Ferris, “Characterizing heterogeneous bacterial surface functional groups using discrete affinity spectra for proton binding," Environmental Science and Technology, vol. 33, no. 24, pp. 4514-4521, 1999.

[37] L. N. Johnson and R. J. Lewis, "Structural basis for control by phosphorylation," Chemical Reviews, vol. 101, no. 8, pp. 22092242, 2001.

[38] J. DeRuiter, "Carboxylic Acid Structure and Chemistry: Part 1," 2005, http://www.auburn.edu/ deruija/pdal_acids1.pdf.

[39] N. L. Bauld, “Amines,” 2005, http://research.cm.utexas.edu/ nbauld/CHAPTER\%2021.htm.

[40] P. X. Sheng, Y.-P. Ting, J. P. Chen, and L. Hong, "Sorption of lead, copper, cadmium, zinc, and nickel by marine algal biomass: characterization of biosorptive capacity and investigation of 
mechanisms," The Journal of Colloid and Interface Science, vol. 275, no. 1, pp. 131-141, 2004.

[41] J. DeRuiter, "Amides and related functional groups," 2005, http://www.auburn.edu/ deruija/pdal_amides.pdf.

[42] G. M. Gadd, "Biosorption: critical review of scientific rationale, environmental importance and significance for pollution treatment," Journal of Chemical Technology and Biotechnology, vol. 84, no. 1, pp. 13-28, 2009.

[43] D. S. Domozych, "Algal Cell Walls," in eLS, John Wiley \& Sons, Chichester, UK, 2011.

[44] T. A. Davis, B. Volesky, and A. Mucci, "A review of the biochemistry of heavy metal biosorption by brown algae," Water Research, vol. 37, no. 18, pp. 4311-4330, 2003.

[45] Periodic table, Lenntech, 2014, http://www.lenntech.com/periodic/periodic-chart.htm.

[46] R. Kayestha, Sumati, and K. Hajela, "ESR studies on the effect of ionic radii on displacement of $\mathrm{Mn}^{2+}$ bound to a soluble $\beta$ galactoside binding hepatic lectin," FEBS Letters, vol. 368, no. 2, pp. 285-288, 1995. 

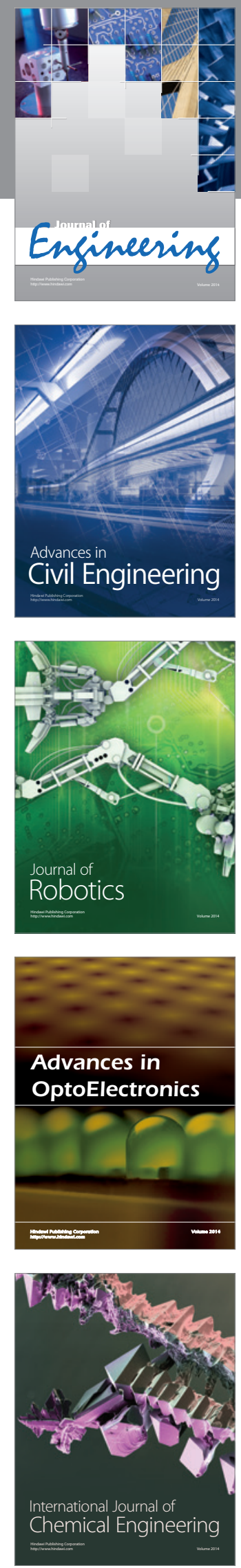

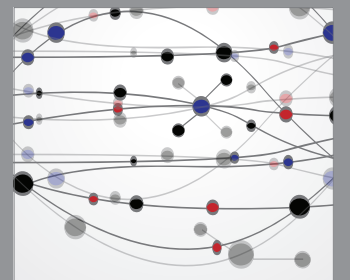

The Scientific World Journal
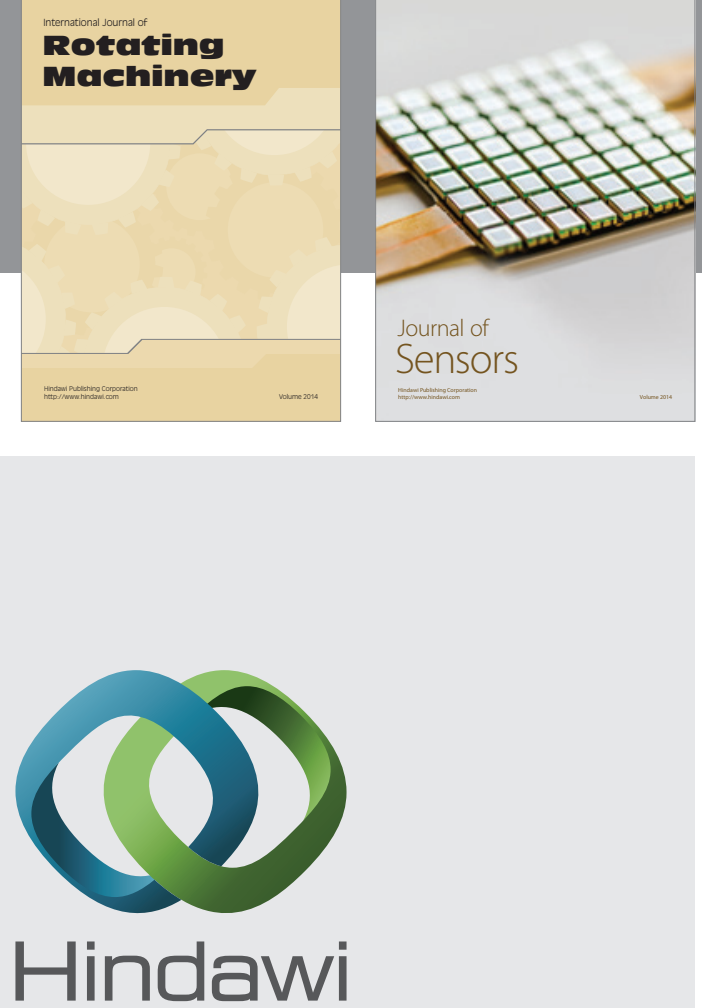

Submit your manuscripts at http://www.hindawi.com
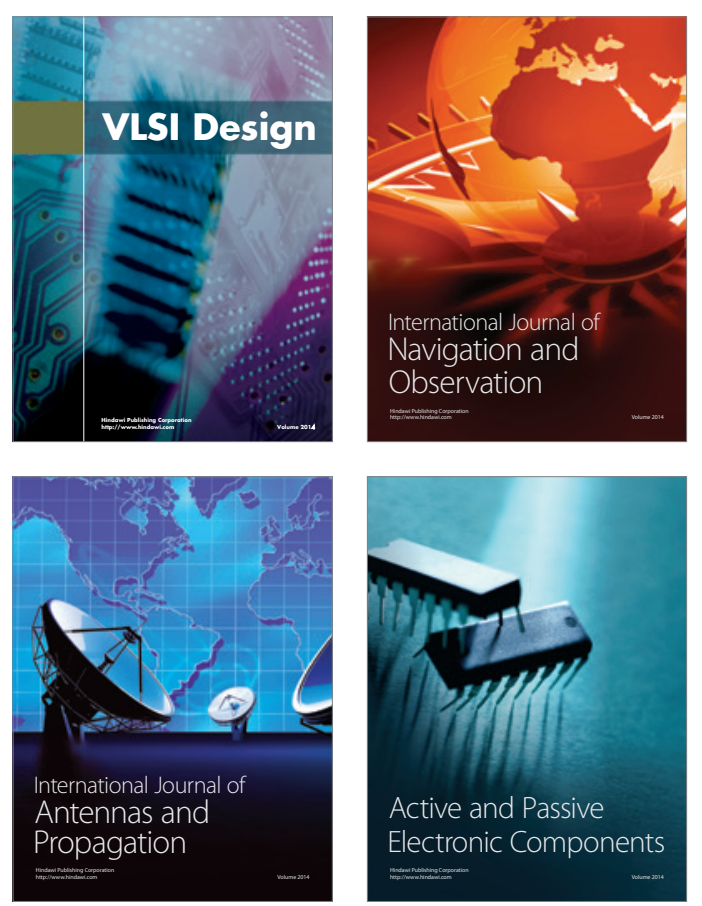
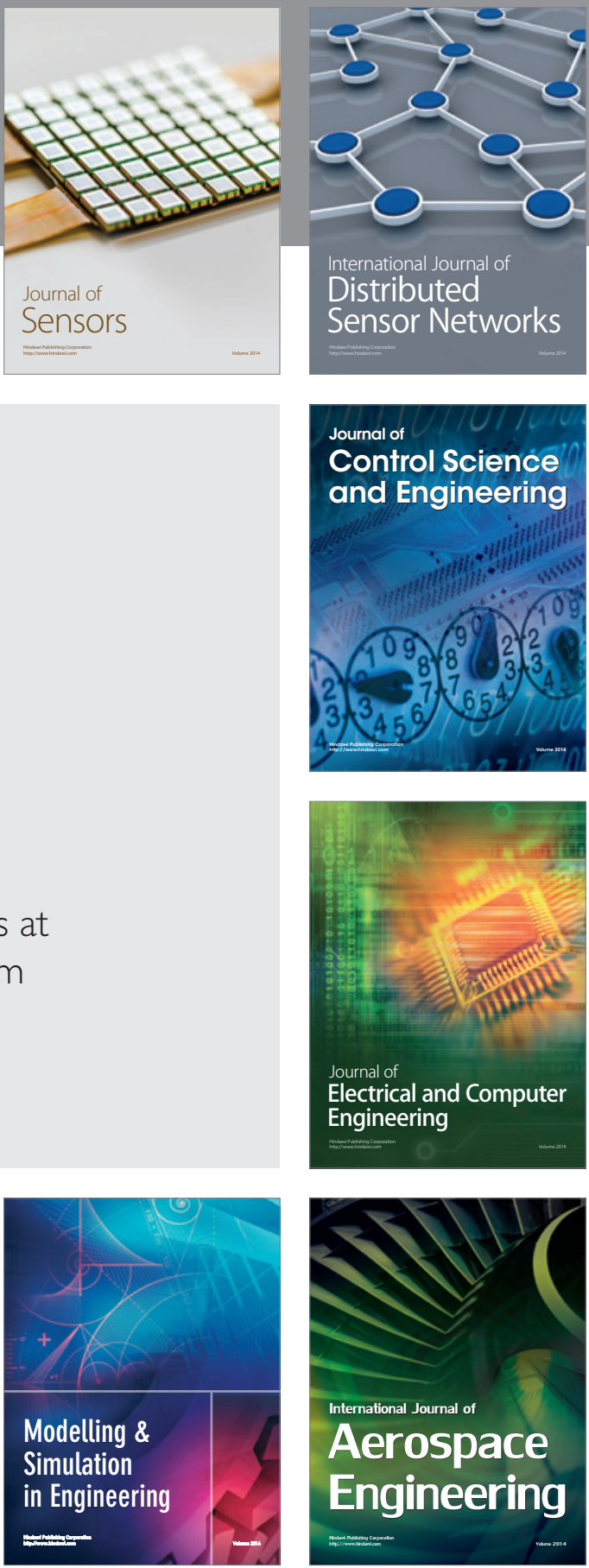

Journal of

Control Science

and Engineering
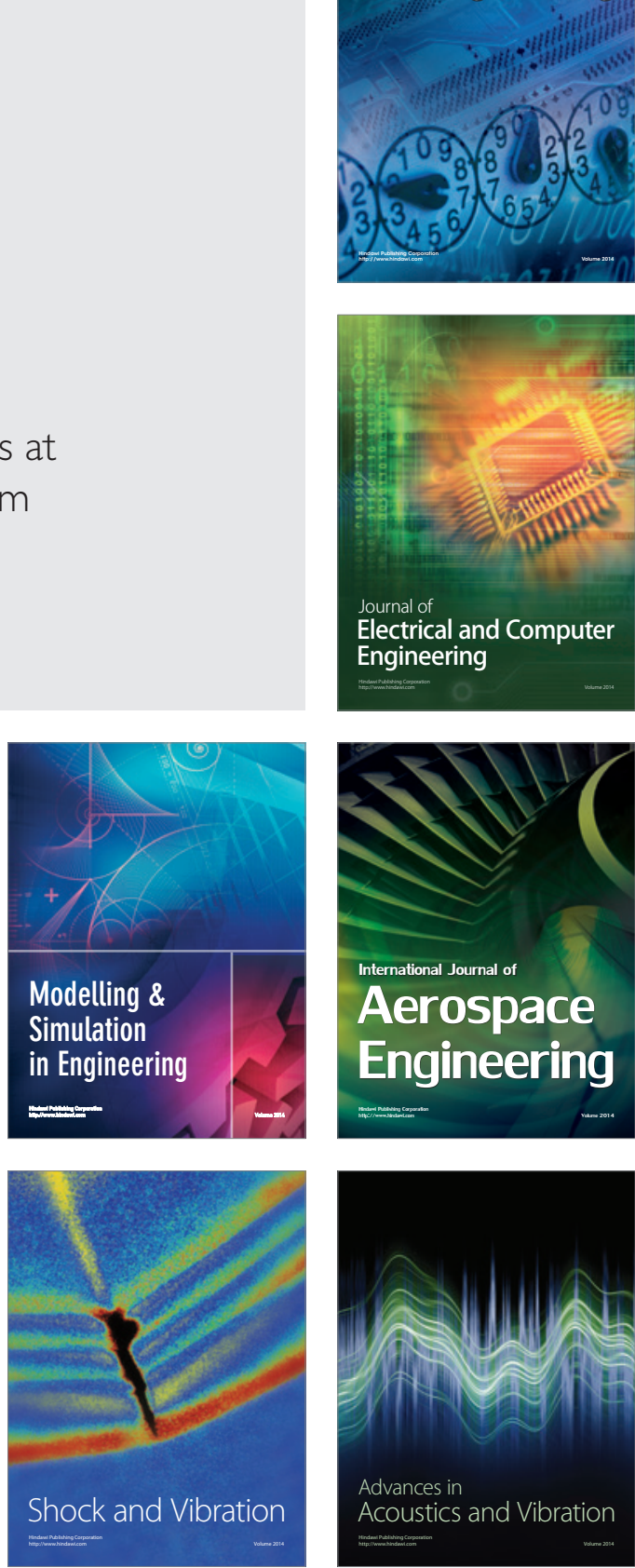